\title{
Airway Epithelial Dynamics in Allergy and Related Chronic Inflammatory Airway Diseases
}

\author{
Anu Laulajainen-Hongisto ${ }^{1,2 *}$, Sanna Katriina Toppila-Salmi3,4, Annika Luukkainen ${ }^{3}$ and \\ Robert Kern ${ }^{5}$
}

1 Department of Otorhinolaryngology, Helsinki University Hospital, University of Helsinki, Helsinki, Finland, ${ }^{2}$ Laboratory of Cellular and Molecular Immunology, Institute of Microbiology of the Czech Academy of Sciences, Prague, Czechia, ${ }^{3}$ Haartman Institute, Medicum, University of Helsinki, Helsinki, Finland, ${ }^{4}$ Skin and Allergy Hospital, Helsinki University Hospital and University of Helsinki, Helsinki, Finland, ${ }^{5}$ Department of Otolaryngology, Northwestern University Feinberg School of Medicine, Chicago, IL, United States

Allergic rhinitis, chronic rhinosinusitis, and asthma are highly prevalent, multifactorial chronic airway diseases. Several environmental and genetic factors affect airway epithelial dynamics leading to activation of inflammatory mechanisms in the airways. This review links environmental factors to host epithelial immunity in airway diseases. Understanding altered homeostasis of the airway epithelium might provide important targets for diagnostics and therapy of chronic airway diseases.

OPEN ACCESS

Edited by:

Wei-jie Guan,

First Affiliated Hospital of Guangzhou

Medical University, China

Reviewed by:

Woo-Jung Song,

University of Ulsan, South Korea

Cesar Picado,

University of Barcelona, Spain

*Correspondence:

Anu Laulajainen-Hongisto anu.laulajainen-hongisto@hus.fi

Specialty section:

This article was submitted to

Molecular Medicine,

a section of the journal

Frontiers in Cell and Developmental

Biology

Received: 28 November 2019

Accepted: 10 March 2020

Published: 27 March 2020

Citation:

Laulajainen-Hongisto $A$

Toppila-Salmi SK, Luukkainen A and Kern R (2020) Airway Epithelial Dynamics in Allergy and Related Chronic Inflammatory Airway Diseases. Front. Cell Dev. Biol. 8:204. doi: 10.3389/fcell.2020.00204
Keywords: asthma, chronic rhinosinusitis, epithelium, allergic rhinitis (AR), inflammation

\section{BULLET POINTS}

Chronic airway diseases are mediated by several, in part unknown, host epithelial- and environment dependent mechanisms.

- The typical disease-leading host-environmental effects are on mucociliary clearance and other innate immunity functions of the epithelial barrier (such as epithelial junctions, pattern recognition, self-renewal, activation of adaptive immunity, metabolism).

- In AR, allergens are able to penetrate airway mucosa by their proteolytic, lipid-binding, and microbial-mimicking properties through the epithelial cells and/or between them.

- Airway viral infections have been implicated in development and exacerbations of AR and asthma, however, their role in CRS pathogenesis remains unclear.

- Airborne irritants, such as cigarette smoke, disrupt epithelial junction proteins and transepithelial resistance, and contribute to CRS alone or together with viral infection.

- Air pollutants might predispose to CRS via aberrant epithelial function.

- Microbiome dysbiosis likely contributes to CRS pathogenesis.

- S. aureus colonization indirectly/directly affects mucosal barrier function, leading to a Th2 type inflammation pattern.

- The role of fungi has been shown in at least two CRS phenotypes, fungal balls, and allergic fungal rhinosinusitis (AFRS).

\section{INTRODUCTION}

In allergic rhinitis (AR), allergens bind to specific immunoglobulin (Ig)E, leading to rhinorrhea, obstruction, itch, sneeze, and fatigue in sensitized subjects (Wise et al., 2018). AR is interlinked to co-morbidities including asthma, allergic conjunctivitis and atopic dermatitis. However, its role in chronic rhinosinusitis (CRS) is not clear. Chronic inflammation, mucus hypersecretion, 
edema, variable obstruction, and fatigue characterize asthma. In both children and adults, asthma encompasses different, overlapping phenotypes (Wenzel, 2012; Kaur and Chupp, 2019). Allergic multi-morbidity and predominance in males characterize childhood-onset asthma, whereas adult-onset asthma is more common in females and includes a wide variety of allergic [T helper (Th) Type 2 (Th2)-high] and nonallergic (often Th1-high) phenotypes (Wenzel, 2012; Frohlich et al., 2017). Severe eosinophilic forms, e.g., non-steroidal anti-inflammatory drug (NSAID-) exacerbated respiratory disease (NERD), are more common in adults. So far, only few encouraging signals have been found in asthma prevention. The problem may be over-simplification of terminology. Asthma is not a single disease entity, but rather a complex, heterogeneous, and dynamic immunological disorder strongly influenced by gene - environment interactions.

AR and asthma affect over 300 million people worldwide, thus being major public health problems (Gupta et al., 2004; Nunes et al., 2017; GINA, 2018). The prevalence of AR is 1550\% (Pallasaho et al., 2006; Wiksten et al., 2018), its prevalence at teen-age is 13-38\% (Pols et al., 2016; Blaiss et al., 2018; Sterner et al., 2019). The prevalence and socioeconomic impact are difficult to calculate since mild symptoms do not require medical treatment, and most patients outgrow their (especially food) allergies. The prevalence and incidence of, particularly childhood, asthma varies greatly in different parts of the world. After many decades of continuously increasing asthma rates in the Western world, we seem to have reached a plateau in asthma incidence since the beginning of 2000 in many developed countries. In some places even a decrease has been observed. Children migrating from low-income areas to higher socioeconomic areas have a lower prevalence of asthma, suggesting a critical time window for asthma onset in childhood. This suggests the possibility of asthma prevention, since there appear to be predisposing biological factors influenced by the environment. On the other hand, it is likely that within a population, there are genetic factors limiting the number of asthmatics. It should be kept in mind that up to $85 \%$ of asthma patients have AR, and on the other hand, $15-38 \%$ of AR patients have asthma (Mésidor et al., 2019). Of adults with asthma, $80 \%$ have rhinitis, and 50\% have chronic rhinosinusitis (Jarvis et al., 2012).

Chronic rhinosinusitis (CRS) is a chronic symptomatic inflammation of the sinonasal tract, with a prevalence of 310\% (Fokkens et al., 2012; Dietz de Loos et al., 2019; Hirsch et al., 2019). CRS presents with (CRSwNP) or without (CRSsNP) nasal polyps (NP), and is defined by typical subjective symptoms (facial pain, post-nasal drip, obstruction, discharge) lasting for at least 12 weeks, objectively confirmed by either positive endoscopic findings (oedema, mucus secretions, polyps) or positive radiologic findings (mucosal inflammation on sinus CT scans). NERD tends to lead to more severe forms of CRS, with NPs and asthma.

The pathomechanisms of asthma, CRS and AR are related to genetic predisposition and aberrant host-immune interactions during development. The environment strongly affects gene expression by epigenetic mechanisms. In addition to genetic predisposition, climate change, population growth, aging, and urbanization impact the increasing prevalence of chronic airway diseases (Kaur and Chupp, 2019).

Genetics and environmental factors can, during development, significantly modulate barrier homeostasis, influencing the predilection toward chronic airway inflammation. The respiratory epithelium is a part of the innate and adaptive immune system, with responsibility for several functions such as mucociliary clearance, pattern recognition, phagocytosis, antigen presentation, signaling, and self-renewal. Airway epithelial dysfunction is related to several airway diseases. The main focus of this review are the pathomechanisms of human airway epithelium in AR, CRS, and asthma. We also briefly discuss altered airway epithelium in bronchiectasis, primary ciliary dyskinesia (PCD), and cystic fibrosis (CF).

\section{GENOME-SCALE EPITHELIAL FACTORS BEHIND AIRWAY DISEASES}

Adult-onset asthma is mediated by activation of molecular pathways leading to persistent mucosal inflammation, variable airway obstruction, inflammation, and tissue remodeling. Genetic and epigenetic variation of the host play key roles (WillisOwen et al., 2018), and airway dysbiosis may be an important trigger (Huang et al., 2015). Childhood-onset asthma appears to be triggered by allergic and infective immune responses, and barrier dysfunction, with a stronger genetic component and higher heritability (Pividori et al., 2019; Schoettler et al., 2019). Genome-wide association studies (GWAS)s have focused on childhood-onset allergic asthma, and the currently identified single nucleotide polymorphisms (SNP)s thus seem to have lower significance in adult-onset asthma (Pividori et al., 2019). Candidate genes for asthma include interleukin (IL)-4, IL-13 and IL-4R, ADRB2, MS4A2, tumor necrosis factor $\alpha(\mathrm{TNF} \alpha)$, cluster of differentiation (CD)14, human leukocyte antigen (HLA)-DRB1 and HLA-DQB1 (Toskala and Kennedy, 2015; Willis-Owen et al., 2018). Combined GWAS and transcriptomewide association tests have identified several genetic loci that may be relevant in asthma, such as the chromosome 17q locus, HLA, IL-6, interferon regulatory factor 4 (IRF4), chemokine (C-C motif) ligand 20 (CCL20), mucin 5AC (MUC5AC), fatty acid desaturase 2 (FADS2), T-box transcription factor 21 (TBX21), runt-related transcription factor 1 (RUNX1), and cytokine and chemokine receptors and signaling molecules (Pividori et al., 2019; Vercelli and Bleecker, 2019). A study showed that asthma remission is associated with genes related to Th2-mediated inflammation, such as IL1RL1-, IL18R1-, and IL-13 (Vonk et al., 2018). A singular GWAS study of a Japanese adult-onset asthma population showed that SNPs of HLA-, thymic stromal lymphopoietin-WD repeat domain 36 (TSLP-WDR36)-, and ubiquitin specific peptidase 38-GRB2 associated binding protein 1 (USP38-GAB1) loci are associated with adult-onset asthma (Hirota et al., 2011).

A missense variant in arachidonate 15-lipoxygenase (ALOX15) is protective against the development of CRSwNP (Kristjansson et al., 2019). In nasal epithelial cells, IL-13 upregulates ALOX15 and promotes eoxtaxin 3 expression, 
likely promoting tissue eosinophilia in CRSwNP patients ( $\mathrm{Li}$ et al., 2019). This pathway may also have a role in epithelial remodeling and barrier dysfunction (Kristjansson et al., 2019). Our transcriptomics of healthy middle turbinate epithelium showed that $75 \%$ of protein encoding genes are expressed, suggesting that the epithelium is a very active organ (Hanif et al., 2019). The importance of barrier-environmental interactions was detected also in a single cell transcriptomics study of nasal epithelium, demonstrating that basal cell memory of Type 2 inflammation leads to persistent dysfunction in CRSwNP patients (Ordovas-Montanes et al., 2018).

Multi-gene expression-based biomarkers of asthma were studied in a Network-identified Transcription Factor framework (Ahsen et al., 2019). ETS translocation variant (ETV4) and Peroxisome proliferator-activated receptor gamma (PPARG) were identified as being the most significant transcription factors. The group further performed validation studies using a nasal epithelium cell line in which both transcription factors were knocked down by siRNA. The respective cell lines produced a significantly decreased amount of IL-8 and IL-6, before poly (I:C) stimulation and before (Ahsen et al., 2019).

\section{EPITHELIAL DYNAMICS IN UPPER AIRWAY DISEASES}

Airway barriers likely have a key role in the development of CRS and AR. In AR, mucosal inflammation is triggered by allergens, together with other environmental factors, leading to IgEmediated mucosal inflammation. In CRS, mucosal inflammation is triggered by a dysfunctional interaction between exogenous agents and the immune system (Liao et al., 2014; Lam et al., 2015; Hoggard et al., 2017). Compared to AR, there is larger inter- and intra-individual variation in the causal factors behind CRS (Figure 1).

\section{Environmental Factors and Upper Airway Epithelium}

Allergen entry into airway mucosa is facilitated by several allergen-, host-, and environment-dependent mechanisms. Allergens are able to penetrate airway mucosa by their proteolytic, lipid-binding, and microbial-mimicking properties (Toppila-Salmi et al., 2015). Mite allergen entry has shown to be facilitated by altered pattern recognition pathways (Lam et al., 2015). Our study group has shown that birch pollen allergens (Bet v1) are able to bind plasma membrane lipid rafts (Toppila-Salmi et al., 2015) and to be transported in caveolar vesicles through the nasal epithelium until they reach mast cells. However, this was detected in allergic patients only (Joenvaara et al., 2009). Moreover, natural birch exposure causes transcriptomics alterations in controls; the fold changes were detected in the nasal epithelial transcripts belonging to Gene Ontology (GO) -category "Immunology". In contrast, transcripts of the AR group were enriched in "Response to virus" and "Cellular transportation" -categories (Mattila et al., 2010). Similar categories have been demonstrated in grass pollen allergy (Roschmann et al., 2011). We performed whole transcriptomic sequencing of nasal epithelial brush samples and demonstrated that birch pollen allergen immunotherapy alters the transcript profile during pollen exposure season toward that of control samples (Hanif et al., 2019). Moreover, the data showed that in AR patients who started with subcutaneous birch pollen immunotherapy, microbiome diversity of nasal epithelium shifted toward that of controls (Hanif et al., 2019).

AR has been shown to associated with active/passive smoking (Saulyte et al., 2014). Taken together, in AR, airborne allergens, as well as tobacco smoke, microbes, and air pollutants are related to the development and aggravation of the disease (Saulyte et al., 2014; Wiksten et al., 2018).

In prevention of CRS development and its progression, commensal organisms likely play a protective role by preventing mucosal colonization by pathogens and putatively providing metabolites improving mucosal health. It has been assumed that microbial agents and microbiome dysbiosis are some of the most important drivers of CRS pathogenesis. S. aureus can directly affect mucosal barrier function and drive Type 2 inflammation (Ryu and Kim, 2020). Molecular sequencing techniques are evolving in power and enable studies on total and relative microbial abundance and their functional activity within the sinonasal tract (Earl et al., 2018). Yet it is important to note intra- and inter-individual variation of the samples and sites of sampling (Copeland et al., 2018). In a cross-sectional study involving sequencing of the $\mathrm{V} 3-\mathrm{V} 4$ region of the $16 \mathrm{~S}$ ribosomal RNA (rRNA) gene in nasal samples, decreased middle meatal microbiome diversity was detected in AR, CRSsNP, and CRSwNP groups compared to controls, with high variability in microbe profiles and even within subjects (Lal et al., 2017). Hence, recent studies support the hypothesis that dysbiosis of the microbiome may trigger mucosal inflammation both in AR and in CRS (Knight et al., 2018). Airway viral infections have been implicated in development and exacerbations of AR and asthma, however, their role in CRS pathogenesis remains unclear. In addition, the role of fungi has been shown in at least two CRS phenotypes, fungal balls and allergic fungal rhinosinusitis (AFRS).

Cigarette smoke extract has been shown to disrupt epithelial junction proteins and transepithelial resistance in an epithelial sinonasal model derived from control patient samples (Tharakan et al., 2016). In addition, cigarette smoke and viral infection might contribute to polyp remodeling (Yamin et al., 2015). Decreased levels of airway epithelial clara cell protein 16 (CC16) are found in the nasal secretions and plasma of patients with CRS and in subjects exposed to high levels of air pollutants (Peric et al., 2018). There is some evidence that heavy metal exposure is related to CRS (Khlifi et al., 2015).

\section{Upper Airway Epithelial Functions During AR and CRS}

The upper airway barrier provides several important innate immunity functions, blockage of microbe entry, and recruitment of leukocytes. Airway epithelium plays a critical role in conducting and humidifying air, responding to trigeminal and olfactory stimuli, and in host defense. The airway epithelial barrier comprises ciliated cells, olfactory cells (in olfactory 


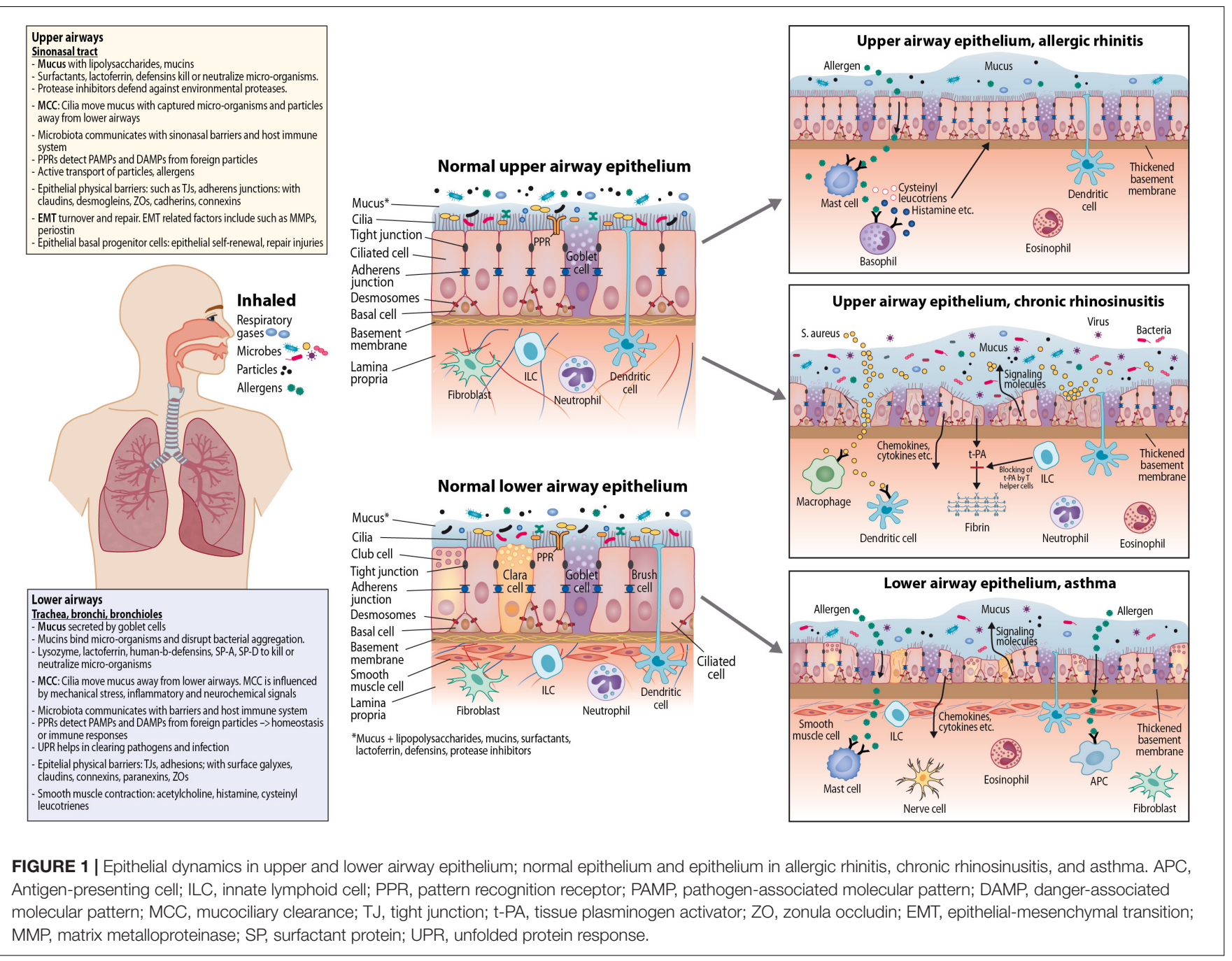

epithelium), mucus-secreting goblet cells, basal cells with progenitor capacity (Bravo et al., 2013) and few chemosensory cells (Kohanski et al., 2018).

Motile cilia consist of microtubules and dynein arms, powered by adenosine triphosphate (ATP) (Knowles et al., 2013; Popatia et al., 2014). Coordinated ciliary beating transports debrisladen mucus from respiratory passages toward the oropharynx (Toppila-Salmi et al., 2015). Genetic and acquired defects in mucociliary flow with increased mucus viscosity are associated with a high incidence of CRS (Cutting, 2005; Gudis et al., 2012). Cilia are coated with mucins and tethered mucopolysaccharides (Toppila-Salmi et al., 2015). Li Y. Y. et al. (2014) detected cilia abnormalities in CRSwNP (Jiao et al., 2015), and that impaired ciliated epithelial differentiation may be mediated via decreased interferon gamma (IFN $\gamma$ ) and IL-13 levels leading to secondary declines in ciliary beat frequency (Jiao et al., 2015). Reduced expression of WDPCP, a ciliogenesis protein, due to inflammatory cytokines resulted in impaired ciliogenesis and cilia function in CRS patients (Ma et al., 2017). Secretory cells produce polymeric gel-forming mucins, such as MUC5AC and MUC5B (Toppila-Salmi et al., 2015). Gel-forming mucins are secreted into the airway lumen and are responsible for the characteristic viscoelastic properties of the mucus gel layer. Tipirneni et al. (2018) identified that dynamic mucus strand velocities from submucosal glands, a major component of mucociliary clearance, were significantly decreased in CRS. Surfactant protein A gene expression has been shown to be increased in CRS and decreased in primary atrophic rhinitis (ElAnwar et al., 2015). In overview, CRS is commonly associated with mucociliary dysfunction.

Both epithelial specification and terminal differentiation are critical to epithelial homeostasis in airway diseases (Ordovas-Montanes et al., 2018). Environmental and mucosal signals regulate epithelial stem-cell self-renewal under normal conditions (Yilmaz et al., 2012) and in CRS (Ordovas-Montanes et al., 2018). Under physiological conditions, environmental and intrinsic signals are able to rapidly alter the composition and function of the epithelium. A study group performed single cell transcriptomics of polyps/scraping epithelium of twelve CRSwNP and nine control subjects. They detected differences in expression of antimicrobial genes by secretory cells, a loss of glandular cell heterogeneity, and that polyp basal progenitor cells were locked to a Type 2 memory (Ordovas-Montanes et al., 2018). Epithelial basal progenitor cells 
are able to migrate and proliferate into ciliated and goblet cells in injured regions.

Upper airway epithelium secretes several cytokines including TSLP, IL-33, and IL-25. These cytokines are released by tissue damage, pathogen recognition or allergen exposure. They effect Th2 cell function either directly or via innate lymphoid cells (ILCs), which in turn produce IL-5, IL-9, and IL-13 (LiconaLimon et al., 2013; Scadding, 2014), related to Th2-type CRS, asthma and AR (Toppila-Salmi et al., 2015). S. aureus colonization is more common in patients with CRSwNP than controls (Tomassen et al., 2016). S. aureus produces serine protease-like protein ( $\mathrm{Spl}$ ), which causes Th2- biased inflammatory responses via TSLP and IL-33 (Stentzel et al., 2017; Ryu and Kim, 2020). S. aureus specific IgE has been associated with both CRSwNP and asthma. S. aureus enterotoxins and $S$. aureus Spls have been found to have allergenic properties (Stentzel et al., 2017; Ryu and Kim, 2020). Type 2 cytokines inhibit t-PA (tissue plasminogen activator) resulting in the deposition of fibrin mesh to form the tissue matrix of NPs (Takabayashi et al., 2013).

Pattern recognition receptors (PRRs) rapidly detect microbial and other foreign molecular patterns and either maintain homoeostasis or induce immune responses. Luukkainen et al. (2018) stimulated a co-culture of peripheral blood mononuclear cells and nasal epithelium, differentiated from stem/progenitor cells, with H3N2-virus and detected rapid activation of monocytes, natural killer (NK)-cells and innate T-cells (MAIT and $\gamma \delta \mathrm{T}$ cells). We demonstrated high baseline nasal epithelial expression of Toll Like receptor (TLR) proteins (TLR1-7, TLR910) and MyD88 both in AR and in controls (Renkonen et al., 2015). After off-seasonal intranasal birch pollen challenge, a negative change in the expression score of TLR1 and TLR6 proteins was detected in the atopic group. Tengroth et al. (2014b) demonstrated abundant TLR3, TLR7, TLR9, RIG-I, and MDA5 in nasal epithelium. The group detected defects in TLR9mediated microbial defense in CRSwNP (Tengroth et al., 2014a). Studies on polyp and control tissue show that increased epithelial TLR2 (Sun et al., 2012) and TLR4 may be related with CRSwNP (Sun et al., 2012; Shimizu et al., 2016; Hu and Li, 2018). Nasal polyp fibroblast activation may occur via TLR2 (Shin et al., 2016a,b; Tsai et al., 2018), TLR4 (Cho et al., 2014, 2016), TLR5 (Shin et al., 2016b), and TLR9 (Park et al., 2018) might be related to polyp B-cell activation (Xu et al., 2014). NOD family PRRs form a major component of the inflammasome, and are related in programmed pro-inflammatory cell death distinct from apoptosis. Jardeleza et al. (2013) detected involvement of inflammasome complexes and their signaling pathways in Staphylococcus aureus -biofilm positive CRSwNP. Lin et al. (2016) detected increased NLRP3 and caspase-1 in eosinophilic CRSwNP, and augmented inflammasome signaling pathway by lipopolysaccharides (LPS). Bitter taste receptors (T2Rs) are G protein-coupled receptors that function as non-classical PRRs. Bacterial quinolones and acyl-homoserine lactones, secreted by gram-negative bacteria, can activate airway T2R-mediated immune responses (Lee and Cohen, 2014; Freund et al., 2018). Linkage studies have demonstrated associations between taste receptor genetics with CRS (Cohen, 2017).
Airway epithelium secretes defense molecules such as surfactant, lactoferrin, and defensins, which kill or neutralize microorganisms. Some evidence suggests that decreased secretion of host defense molecules is associated with CRS (Tieu et al., 2010). Decreased expression levels of palate, lung, and nasal epithelium clone protein (PLUNC), and increased surfactant-B and alpha-defensin levels have been observed in CRSwNP, possibly secondary to loss of glands (Seshadri et al., 2012; Jardeleza et al., 2013; Lin et al., 2016; Tsybikov et al., 2016).

Protease inhibitors regulate environmental proteases that might compromise barrier integrity. Blocking protease allergens with inhibitors reduces allergic responses in AR (Suzuki et al., 2006). Fukuoka et al. (2019) showed that human cystatin SN, an endogenous protease inhibitor, suppresses AR symptoms by inhibiting allergen protease activities and by allergen-specifically protecting nasal TJ barrier. Kouzaki et al. (2016) showed lower host expression of two protease inhibitors (cystatin A and SPINK5) in nasal epithelial cells extracted from patients with eosinophilic CRS compared with control and non-eosinophilic CRS groups. This suggests that an imbalance of proteases and protease inhibitors within the epithelial barrier may contribute to the pathogenesis of Type 2 diseases in general (Wu et al., 2018).

Epithelial cells undergo turnover and repair after injury through epithelial to mesenchymal transition (EMT), with a rapid and normally reversible modulation of the epithelial phenotype toward mesenchymal cells (Toppila-Salmi et al., 2015). During EMT, epithelial cells lose cell-cell polarity and adhesion to become migratory. They get mesenchymal features such as alpha-smooth muscle actin, vimentin, matrix metalloproteinases (MMPs), and transcription factors. In CRS, aberrant epithelial structure and function may lead to increased permeability to foreign material suggesting this as an early factor in CRS pathogenesis (Pothoven et al., 2015; Ramezanpour et al., 2016; Suzuki et al., 2016; Jiao et al., 2019). Inflammation leads to remodeling with cytokines, mediators, enzymes, and other factors determining the remodeling pattern, not fully depending on the CRS phenotype. The duration and type of inflammation affect mucosal structure and function, and clinical severity of inflammation. Remodeling changes of CRS include fibrosis, basement membrane thickening (BMT), goblet cell hyperplasia, epithelial barrier abnormalities and polyp formation, osteitis, and angiogenesis (Barham et al., 2015; Kuhar et al., 2017).

Periostin promotes adhesion and migration of epithelial cells and is associated with CRSwNP (Ishida et al., 2012; Ohta et al., 2014; Laury et al., 2015; Milonski et al., 2015; Shiono et al., 2015; Wang et al., 2015; Ebenezer et al., 2017; Xu et al., 2017; Wei et al., 2018; Yang et al., 2018; Lehmann et al., 2019) and asthma (Carpagnano et al., 2018; Wei et al., 2018). The EMT process is driven by an array of factors such as WNT, reactive oxygen species, proteases, HIF1, IL-13 Epiregulin, Oncostatin M, and IL-1 (Oyer et al., 2013; Batzakakis et al., 2014; Schleimer, 2017; Aazami et al., 2018; Yang et al., 2018; Tomaszewska et al., 2019). CRSwNP patients have altered expression levels of EMT related factors, such as MMP-1 (Malinsky et al., 2013; Homma et al., 2017), MMP-2 (Malinsky et al., 2013), TIMP-1 (Wang et al., 2012; Muluk et al., 2015), MMP-7 (Yang et al., 2017; Chen et al., 2018), MMP-9 (Wang et al., 2012; Malinsky et al., 2013; 
Yeo et al., 2013; Li et al., 2015; Muluk et al., 2015; Chen et al., 2018; Suzuki et al., 2018; Xiang et al., 2019), TIMP-2 (Li et al., 2015) E-cadherin (Hupin et al., 2014; Kim et al., 2018; Deng et al., 2019). BMT is associated with duration of inflammation independent of tissue eosinophilia (Kountakis et al., 2004; Kuhar et al., 2017). TGF- $\beta$ has been most closely linked to fibrosis, but IL-13 and osteopontin have also been implicated in BMT and fibrosis (Rehl et al., 2007; Van Bruaene and Bachert, 2011; Shi et al., 2013; Schleimer and Berdnikovs, 2017). Abnormalities of the coagulation cascade have also been associated with polyp formation including Factor X, tissue factor and thrombin (Shimizu et al., 2015; Shimizu et al., 2017; Takabayashi et al., 2019). There is some evidence that stem cells in the epithelium maintain a memory for the chronic immature EMT state in severe Type 2 CRS (Lehmann et al., 2019), promoting barrier failure, antigen access, and this inflammation (Pothoven and Schleimer, 2017). Type 2 cytokines inhibit t-PA activity so in the presence of high levels of Type 2 inflammation, the matrix will be retained and grow (Peterson et al., 2012).

Compared to the CRS phenotype, remodeling has been less studied in patients with AR. Li and Li (2019) performed transmission electron microscopy, western blot, and qPCR to nasal epithelial samples of patients with $\mathrm{AR}$ and detected increased autophagosomes, Beclin-1, LC3-II, and Collagen III, along with increased symptom scores, suggesting a link between autophagy and airway remodeling in AR. Taken together, several epithelial phenomena take part in the development and chronicity of the inflammation during CRS and AR.

Epithelial physical barriers are maintained by intercellular junctions. Tight junctions (TJ) are located the most apically, are linked to the cytoskeleton and inhibit solute and water movement through the paracellular space, thus establishing cell polarity (Toppila-Salmi et al., 2015). Inhaled allergens, microbial or viral infections, cytokines, hypoxia, and zinc deficiency are able to affect TJ molecules and epithelial barrier function in the airways (Roscioli et al., 2017; Jiao et al., 2019). Several genes/molecules, such as SPINK5, S100A7, S100A8/9, PCDH1, NDRG1, SPRR, and p63 are involved in modulating the physical barrier function in CRS (Jiao et al., 2019). Yu et al. (2013) demonstrated decreased expression of Epithelium membrane protein 1 (EMP1), a TJ protein, in nasal polyp epithelium compared to control nasal mucosa. Soyka et al. (2012) detected a decreased trans-tissue resistance in biopsy specimens from patients with CRSwNP and also decreased TJ proteins. Suzuki et al. (2016) detected that nasal polyp had a higher expression of claudin (Cld) 1 but lower expression of tricellulin compared with the turbinate. Integrity of the nasal epithelial TJ barrier has been shown to be compromised in Chinese patients with eosinophilic and non-eosinophilic CRSwNP transforming growth factor (TGF)- $\beta 1$ seems to plays an important role in inducing TJ barrier defects (Jiao et al., 2018). Li et al. showed decreased expression of epithelial zonula occludin (ZO)-1, Cld1, desmoglein (DSG)1, and DSG2 in CRSwNP and decreased expression of Cld1, DSG1, and DSG2 in CRSsNP (Li Y. et al., 2014).

Adherens junctions are located more basally than TJs. Epithelial cadherin (E-cadherin) creates intercellular interactions. Together, these junction proteins function to limit intercellular passage of fluid and protect the underlying tissue from exposure to noxious and allergenic stimuli (London and Ramanathan, 2017). Epithelial cell communication is mediated via Gap junction channels, which are formed by connexin proteins enabling cell communication (Kim et al., 2016). Expression of connexins have been demonstrated to be increased in CRS compared to controls (Kim et al., 2016). Hence, epithelial barrier dysfunction may contribute to AR and CRS through allowing increased passage of antigens and exposure of underlying tissue to these stimuli (Toppila-Salmi et al., 2015; London and Ramanathan, 2017).

\section{EPITHELIAL DYNAMICS IN LOWER AIRWAY DISEASES}

Ventilation moves air through the conducting airways to and from the alveoli. The inhaled air contains respiratory gases, particles, microbes, and toxins. Defense mechanisms preventing the entry of unwanted substances into the lung tissue and circulatory system include the branching structure of the conducting airways, the layers of mucus covering the airways, mucociliary clearance, contraction of the airway smooth muscle, the tight adhesions of airway epithelial cells (AEC) and their underlying stroma, and the production of host-defense molecules regulated by exposure to toxins, pathogens and cytokines (Lambrecht and Hammad, 2012; Whitsett and Alenghat, 2015).

Asthma is a chronic pulmonary disease characterized by airway inflammation, airway hyperreactivity, and recurrent, reversible airway obstruction. Several asthma phenotypes related to disease mechanisms exist; these include childhood-onset allergic asthma, adult-onset eosinophilic asthma, obesity-related asthma, and neutrophilic asthma (Wenzel, 2012). Airway inflammation is initiated by AECs as a defense against inhaled pathogens and particles, e.g., allergens. In asthma these defense mechanisms are hyperreactive. Excessive mucus production contributes to airway obstruction, which is mainly caused by contraction of airway smooth muscle (Erle and Sheppard, 2014; Figure 1).

\section{Environmental Factors, Epithelium, and Asthma}

The risk factors for asthma include AR and allergic conjunctivitis, atopic dermatitis, exposure to air pollution, cigarette smoke, occupational risk factors, obesity, and genetic factors (Polosa and Thomson, 2013; Ilmarinen et al., 2015; Toskala and Kennedy, 2015; Willis-Owen et al., 2018; Toppila-Salmi et al., 2019). Childhood-onset asthma has a stronger genetic component than adult asthma and is triggered due to dysregulated allergy and epithelial barrier function (Pividori et al., 2019; Schoettler et al., 2019). The development of adult asthma is more likely in patients with an accumulation of several risk factors and with allergic multimorbidities (Hallit et al., 2019; Pividori et al., 2019; ToppilaSalmi et al., 2019). Asthma, rhinitis, and chronic rhinosinusitis often co-exist (Jarvis et al., 2012). 
The airway microbiome communicates with the respiratory epithelium and has an important role in maintaining airway health (Hansel et al., 2013; Morris et al., 2013; Huang et al., 2015). Disruption of normal mucociliary clearance in smokers, and in patients with asthma or cystic fibrosis (CF) affects airway microbiome homeostasis and may lead to disease (Dickson et al., 2013; Hansel et al., 2013; Morris et al., 2013). Early childhood respiratory tract microbial exposure influences immune responses, regulating Th1 and Th2 immunity and affecting future asthmatic responses (Busse et al., 2010; Ege et al., 2011). In children with a family history of asthma, the risk of asthma is increased by severe respiratory syncytial virus (RSV) infections (Sigurs et al., 2000). Virus infections of the respiratory tract, especially caused by rhinoviruses, associate with asthma exacerbations (Busse et al., 2010). Patients with asthma may have deficient IFN $\gamma$ response leading to prolonged and more severe viral infections, deficient IFN $\gamma$ response has also been linked to Th2 type immune reaction (Lisspers et al., 2018).

\section{Epithelial Functions in Asthma}

The trachea, bronchi, and bronchioles are mainly lined by ciliated pseudostratified epithelium. Also serous, club, goblet and neuroendocrine cells, and smooth muscle cells are found in the airways.

In patients with asthma and bronchiectasis, excessive goblet cell differentiation, and mucus production are common (Whitsett and Alenghat, 2015).

Submucosal glands in the trachea and bronchi are lined by basal, ciliated, myoepithelial, serous and goblet cells, and secrete fluids and host-defense molecules such as lysozyme, lactoferrin, human-b-defensins, and surfactant proteins $\mathrm{A}$ and D. Mucins are large glycoproteins mainly produced by goblet cells (mucin granules), they have important functions in cellcell interaction, EGFR signaling and airway protection (Thai et al., 2008; Voynow and Rubin, 2009). Mucins tied to AECs (MUC4, MUC13, MUC16, MUC21) create a barrier that by pathogen or host-associated proteases can shed, enabling the unwanted microbe to be removed by mucociliary clearance. Secreted airway mucins (MUC5B, MUC5AC, and MUC2) form a microbe binding, bacterial aggregation disrupting gel. The expression of secreted mucins is induced by transcription factors e.g., MAPK, STAT6, and inhibited by transcription factors FOXa2 and TTF-1 (Maeda et al., 2011; Alevy et al., 2012; Whitsett and Alenghat, 2015).

Dysfunctional movement of the cilia leads to impaired mucociliary clearance, accumulation of thick mucus and recurrent infections. Primary ciliary dyskinesia (PCD) patients have structurally abnormal cilia, decreased production of nitric oxide by AECs, bronchiectasis, and chronic bacterial infections of both the upper and lower airways (Knowles et al., 2013; Popatia et al., 2014). Secondary impairment of ciliary movement, e.g., due to smoking or CF, leads to abnormalities in airway hydration and mucus production. Ciliary function is influenced by mechanical stress, inflammatory and neurochemical signals, including paracrine signals of AECs. The gap junctions between cells exchange responses induced by these stimuli, connexin
Cnx43 plays an important role in this (Martin and Prince, 2008; Bou Saab et al., 2014).

The respiratory epithelium recognizes pathogen-associated molecular patterns (PAMP), from commensal microbes or pathogens, and danger-associated molecular patterns (DAMP), from cell stress or cell death. Membrane associated or cytosolic PRRs expressed in AECs recognize PAMPs and DAMPs, resulting in signaling via TLRs, mitogen-activated protein kinase (MAPK), IRF and nuclear factor- $\kappa \mathrm{B}(\mathrm{NF}-\kappa \mathrm{B})$ family transcription factors, reactive oxygen species (ROS), and Janus kinase - signal transducer and activator of transcription (JAKSTAT) signaling pathway, some of which also interact (Athari, 2019). The resulting cytokine and chemokine signaling and production of antimicrobial proteins leads to recruitment and activation of innate and adaptive immune system cells, and regulation of barrier function (Voynow and Rubin, 2009; Lambrecht and Hammad, 2012; Erle and Sheppard, 2014; Whitsett and Alenghat, 2015). Also unfolded protein response (UPR) helps in clearing pathogens and infection by linking the synthesis of misfolded proteins encoded by pathogens to inflammatory signaling, activating apoptosis and necrosis to remove the pathogens and infected epithelial cells (Osorio et al., 2013). Alveolar macrophages, but also AECs ingest infected and apoptotic cells by phagocytosis (Juncadella et al., 2013).

TLR4 can be activated by LPS, cigarette smoke, RSV, and inflammatory cytokines (Monick et al., 2003; Armstrong et al., 2004; Pace et al., 2008). Allergens cause TLR4-dependent

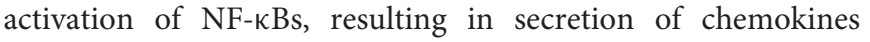
and cytokines, such as IL-33, TSLP, and IL-25, and activation and recruitment of pulmonary dendritic cells, Type 2 innate lymphoid cells (ILC2 cells) and Th2 lymphocytes (Hammad et al., 2009; Tan et al., 2010; Lambrecht and Hammad, 2014). Interferons are secreted to defend against viral infections, and in patients with asthma, deficient IFN $\gamma$ response may lead to prolonged and more severe viral infections (Lisspers et al., 2018). A study group performed expression profiling of airway epithelium that demonstrated similar cytokine profiles of EGR1, DUSP1, FOSL1, JUN, MYC, and IL-6 after stimulation of AECs with either dsRNA or with house dust mite, however, both triggers also induced a specific response (e.g., ATF3, FOS, and NF-кB1) (Golebski et al., 2014). It could thus be possible that microbial infection and its underlying immune dysfunction might be a phenotypic or clinical feature of both atopic and non-atopic chronic conditions in the airways rather than only a secondary effect (Juhn, 2014).

Epithelial extracellular vesicles (EVs) can transfer microRNAs (miRNAs). In particular miR-34a, miR-92b, and miR-210 may have a role in the development of the Th 2 response in asthma (Bartel et al., 2019). As a sign of epithelial dysfunction in asthma, AEC DNA methylation is different in asthmatics vs. non-asthmatics (Clifford et al., 2019).

A recent study shows that asthmatic Type 2 inflammation and airway hyperresponsiveness are related to mast cell infiltration into the airway epithelium and that AECs and mast cells communicate through IL-33 signaling that regulates 
inflammation (Altman et al., 2019). In allergic asthma, the inflammatory process is initiated by $\mathrm{Th} 2$ cells that produce cytokines, such as IL-4, IL-5, IL-9, IL-13, leading to the production of IgE, eosinophilia, and goblet cell hyperplasia (Whitsett and Alenghat, 2015; Athari, 2019). Pathways to regulate goblet cell hyperplasia are also activated by epidermal growth factor receptor (EGFR) (Tyner et al., 2006). Contraction of the airway smooth muscle, resulting in airway narrowing, is induced by acetylcholine released from efferent parasympathetic nerves, or by histamine and cysteinyl leukotrienes released from mast cells and basophils (Erle and Sheppard, 2014). Asthma is modulated also by Th9 and Th17 cells, that produce IL-17F, IL-22, and IL-17A inducing airway inflammation and enhancing smooth muscle contractility (Kudo et al., 2013). Airway epithelium and smooth muscle cells communicate also via epithelial cell-derived endothelin-1 (Lan et al., 2018). Airway hyperresponsiveness is linked to IL-4 (Athari, 2019), and also to IL-13 and IL17 by inducing RhoA expression, and $\mathrm{Ca}^{2+}$ sensitization of bronchial smooth muscle (Erle and Sheppard, 2014). Airway smooth muscle contractibility is also increased by $\mathrm{TNF} \alpha$ (Goto et al., 2009).

The barriers created by AECs are important for the health and normal function of the airways. Increased epithelial permeability and inflammation with disruptions in the TJ complexes may affect the pathogenesis of asthma and other pulmonary diseases (Georas and Rezaee, 2014). Barriers of AECs include secretory products, surface glycocalyces, membranes and intracellular junction proteins consisting of claudins, connexins, paranexins, adhesions, and ZOs. Pulmonary cells claudins, such as claudin 3 (Cld3), Cld4, and Cld18 create interlocking structures forming these TJs (Whitsett and Alenghat, 2015).

The alveoli are lined by only two cell types, simple squamous alveolar squamous epithelium type I (90\%) or cuboidal type II cells. The type II alveolar cells are the main progenitor cells for alveolar cells. The type I alveolar cells are in close interaction with the pulmonary capillary endothelial cells to ensure exchange of respiratory gases. Surfactant lipids and proteins secreted by type II epithelial cells diminish alveolar surface tension. They ensure optimal surface tension, prevention of alveolar collapse but ensuring elasticity and gas exchange. The type II alveolar cells have many lipid-rich lamellar bodies, microvilli on the apical surfaces and express surfactant homeostasis mediating lipids and proteins, such as surfactant protein (SP)-A, SP-B, SP-C, SP-D5. SPs bind, aggregate and/or directly kill microbial pathogens, enhancing their clearance by immune system cells (Numata et al., 2010; Whitsett et al., 2010). SP-A and SP-D belong to collectins (innate host-defense proteins); they bind with PAMPs. SP-A and SP-B form tubular myelin that together with lipids forms a pool of surfactant and host-defense proteins (e.g., lysozymes and SP-C). This enhances opsonization and killing of pathogens by alveolar macrophages and regulates macrophage, neutrophil, and lymphocyte activity (Hartshorn, 2010; Whitsett and Alenghat, 2015). Loss of SP-B or SP-C production impairs both alveolar barrier and macrophage functions and causes tissue injury and inflammation (Akei et al., 2006). The volume and composition of surfactant pools are maintained by de novo synthesis, reuptake and recycling by alveolar type II cells, also by the catabolic activity of alveolar macrophages, in processes partly regulated by granulocyte-macrophage colonystimulating factors (GM-CSF) (Whitsett et al., 2010; Whitsett and Alenghat, 2015). Impairment of GM-CSF signaling has been associated with susceptibility to bacterial and viral infections (Tourdot et al., 2008).

Two types of macrophages can be found in the lungs, alveolar macrophages and interstitial macrophages (Jiang and Zhu, 2016). Macrophages can roughly be classified to classically activated (M1) and alternatively activated (M2) macrophages, mirroring Th1 and Th2 polarization of T cells. M1 macrophages are induced by INF $\gamma$ and LPS, they are involved in pathogen clearance. M2 macrophages are induced by IL-4 and IL-13, and are involved in wound healing and anti-inflammatory responses (Sica and Mantovani, 2012; Liu et al., 2013; ShapouriMoghaddam et al., 2018). It is possible that M1-mediated inflammation in the adipose tissue of obese patients enhances M2-mediated asthmatic inflammation of the lungs (Sharma et al., 2017). CD163 is a known marker for M2 macrophages, it seems to have a role in airway hyperresponsiveness and asthma (Jiang and Zhu, 2016; Tokunaga et al., 2019). Alveolar macrophages respond to pathogens, sense antigens and activate innate and acquired immunity. During infection, they clear apoptotic cells and inhibit inflammation (Westphalen et al., 2014). Alveolar epithelial cells and macrophages directly communicate via Cnx43 channels to modify inflammatory signals and regulate cytokine and chemokine expression in response to pathogens (Westphalen et al., 2014; Whitsett and Alenghat, 2015). Interventions to modulate phenotypes of alveolar macrophages may have therapeutic potential in the treatment of asthma (Jiang and Zhu, 2016).

\section{Epithelial Functions in Bronchiectasis, Primary Ciliary Dyskinesia, and Cystic Fibrosis}

Bronchiectasis results from severe airway infection and inflammation. Its pathomechanisms are in part unknown. Patients with bronchiectasis have irreversible bronchial dilatation with excessive goblet cell differentiation and mucus production (Whitsett and Alenghat, 2015). Defective airway host-defense, infections and inflammation contribute to the development of bronchiectasis (Guan et al., 2018).

In PCD patients, the dysfunctional movement of cilia leads to impaired mucociliary clearance, accumulation of thick mucus, recurrent infections, and may lead to the development of bronchiectasis with chronic bacterial infections (Knowles et al., 2013; Popatia et al., 2014). Chronic infections occur both in the lower and upper airways. CRS and CRSwNP are common in patients with bronchiectasis according to a Spanish study (Guilemany et al., 2009). However, Chinese adults with bronchiectasis seem to have less CRS than in western populations (Guan et al., 2015).

Bronchiectasis is also a common manifestation of cystic fibrosis (CF) (Guan et al., 2018). Patients with CF have mutations in the gene encoding cystic fibrosis transmembrane 
conductance regulator (CFTR), leading to inhibition of $\mathrm{Cl}^{-}$and $\mathrm{HCO}_{3}^{-}$transport by airway and submucosal gland epithelial cells. This results in thickening of mucus, which leads to flawed mucociliary clearance, secondary impairment in ciliary movement and chronic bacterial infection (Whitsett and Alenghat, 2015), both in lungs and paranasal sinuses (Hamilos, 2016). CRSwNP occurs with increased prevalence in CF patients (Hamilos, 2016). There is evidence that increased intracellular levels of $\mathrm{Cl}^{-}$may be associated with chronic inflammation in bronchiectasis and CF (Zhang et al., 2018).

There is a strong association of a homozygous mutation of the chloride transport gene (CFTR) with childhood-onset CRS (Kim and Ober, 2019). Heterozygous CFTR mutations are also associated with CRS signals, albeit less than in clinical CF, with disease usually presenting in adulthood (Hsu et al., 2013; Yoo and Suh, 2017). The impaired mucociliary flow seen with CFTR mutations is presumed to intensify microbial exposure, also affecting disease course (Wang et al., 2000). The importance of CFTR in childhood-onset CRS suggests that also other barrierrelated genes might play a role in CRS initiation.

Much of the non-protein encoding DNA encodes functional RNAs, important in gene regulation. A microarray analysis of bronchial brushings showed that 1,063 out of over 30,000 long non-coding RNA transcripts had different expression between $\mathrm{CF}$ and non-CF individuals, the pathologic processes in $\mathrm{CF}$ patients' airway epithelium are thus possibly partly driven by non-coding RNAs, possibly altering gene expression regulation (McKiernan et al., 2014).

\section{EPITHELIUM AND UNITED AIRWAY CONCEPT}

Most genes related to viral responses were similarly induced in upper and lower airways, in a study involving poly (I:C) -stimulated intra-individual primary nasal and bronchial epithelial cells, however, asthma patients had impaired induction of several interferon-related genes (Wagener et al., 2014). In a cross-sectional study of asthmatic children; transcriptomic sequencing was performed in 10 children and targeted sequencing in 40 children. Expression profiles reassembled in nasal and bronchial brushings, were specific to asthma independently of atopic status, and clustering analysis identified Th2-high and low subjects differentiated by expression of 70 genes (such as IL-13, IL-5, periostin, CLCA1, SERPINB2) (Poole et al., 2014). These Th2-high subjects more likely had atopy, atopic asthma, eosinophilia, and rhinitis. Hence, using less invasive nasal brushing samples and epithelial profiling may be clinically applicable when assessing asthma endotype and specific treatment. There is evidence that nasal epithelial cells could act as surrogates to bronchial epithelial cells in studies investigating airway inflammation (McDougall et al., 2008; Roberts et al., 2018). This is, however, not always feasible, bronchial epithelial cells are more susceptible to rhinovirus infection than nasal epithelial cells (Lopez-Souza et al., 2009).

\section{CONCLUSION AND FUTURE NEEDS}

Airway epithelium has important innate immune functions, all these functions seem to be essentially involved in the development of AR, CRS, and asthma.

Under normal conditions, several airborne factors are inhaled through the respiratory system and they interact with the airway barriers. In healthy individuals, the airway barrier limits the entry of pathogens and allergens, regulates the interaction with the host immune system promoting homeostasis. In AR, CRS, and asthma, barrier penetration results in inflammatory responses that are dynamic and heterogeneous and not clearly matched to the inciting agents. Asthma is not a single disease entity, and childhood-onset and adult-onset asthma have different backgrounds regarding their genetics, association with AR and CRS, possibly also differences in microbehost interactions. Currently, only triggering factors of AR and other allergic diseases are known. Of note, allergens have an impact in pathogenesis and exacerbation of atopic asthma, both childhood-onset and adult-onset. Development of CRS and asthma seem to involve several triggering factors, such as microbiome dysbiosis, which together with host barrier immunity leads to development and aggravation of the disease. However, it is not fully understood whether microbiome dysbiosis is a primary or secondary event. Microbiota changes during development, aging, sporadic events, treatment, between anatomic compartments, and between individuals. Well-controlled studies, and the latest methodology are mandatory to identify putative causal relationships between functionally active microbiota and chronic airway diseases. Bronchial epithelial sampling is more complicated, whereas nasal epithelial sampling can be performed easily, and with little harm. Genome-scale experiments and genome-environmental interaction analyses are important approaches when searching for pathways of chronic upper airway diseases.

\section{AUTHOR CONTRIBUTIONS}

All authors participated in writing of this article and critically reviewed the final article text.

\section{FUNDING}

The study was supported in part by research grants of Aatos Erkko Foundation, Finnish Medical Society Duodecim, Finnish ORL-HNS Foundation, Finnish Society of Allergology and Immunology, State funding for university-level health research (TYH2018103 and TYH2019322), Tampere Tuberculosis association, Väinö and Laina Kivi Foundation, and Yrjö Jahnsson Foundation.

\section{ACKNOWLEDGMENTS}

We wish to thank Helena Schmidt for her work with the figure. 


\section{REFERENCES}

Aazami, H., Seif, F., Ghalehbaghi, B., Mohebbi, A., Ahmadi, A., Babaheidarian, P., et al. (2018). Levels of total IgA and IgA subclasses in the serum of chronic rhinosinusitis patients. Med. J. Islam. Repub. Iran 32:94. doi: 10.14196/mjiri.32. 94

Ahsen, M. E., Chun, Y., Grishin, A., Grishina, G., Stolovitzky, G., Pandey, G., et al. (2019). NeTFactor, a framework for identifying transcriptional regulators of gene expression-based biomarkers. Sci. Rep. 9:12970. doi: 10.1038/s41598-01949498-y

Akei, H., Whitsett, J. A., Buroker, M., Ninomiya, T., Tatsumi, H., Weaver, T. E., et al. (2006). Surface tension influences cell shape and phagocytosis in alveolar macrophages. Am. J. Physiol. Lung Cell. Mol. Physiol. 291, L572-L579.

Alevy, Y. G., Patel, A. C., Romero, A. G., Patel, D. A., Tucker, J., Roswit, W. T., et al. (2012). IL-13-induced airway mucus production is attenuated by MAPK13 inhibition. J. Clin. Invest. 122, 4555-4568. doi: 10.1172/JCI64896

Altman, M. C., Lai, Y., Nolin, J. D., Long, S., Chen, C. C., Piliponsky, A. M., et al. (2019). Airway epithelium-shifted mast cell infiltration regulates asthmatic inflammation via IL-33 signaling. J. Clin. Invest. 129, 4979-4991. doi: 10.1172/ JCI126402

Armstrong, L., Medford, A. R., Uppington, K. M., Robertson, J., Witherden, I. R., Tetley, T. D., et al. (2004). Expression of functional toll-like receptor-2 and 4 on alveolar epithelial cells. Am. J. Respir. Cell Mol. Biol. 31, 241-245. doi: 10.1165/rcmb.2004-0078oc

Athari, S. S. (2019). Targeting cell signaling in allergic asthma. Signal Transduct. Target. Ther. 4:45. doi: 10.1038/s41392-019-0079-0

Barham, H. P., Osborn, J. L., Snidvongs, K., Mrad, N., Sacks, R., and Harvey, R. J. (2015). Remodeling changes of the upper airway with chronic rhinosinusitis. Int. Forum Allergy Rhinol. 5, 565-572. doi: 10.1002/alr.21546

Bartel, S., La Grutta, S., Cilluffo, G., Perconti, G., Bongiovanni, A., Giallongo, A., et al. (2019). Human airway epithelial extracellular vesicle miRNA signature is altered upon asthma development. Allergy 75, 346-356. doi: 10.1111/all. 14008

Batzakakis, D., Stathas, T., Mastronikolis, N., Kourousis, C., Aletras, A., and Naxakis, S. (2014). Adhesion molecules as predictors of nasal polyposis recurrence. Am. J. Rhinol. Allergy 28, 20-22. doi: 10.2500/ajra.2014.28.3962

Blaiss, M. S., Hammerby, E., Robinson, S., Kennedy-Martin, T., and Buchs, S. (2018). The burden of allergic rhinitis and allergic rhinoconjunctivitis on adolescents: a literature review. Annals Allergy Asthma Immunol. 121, 43-52.e3. doi: 10.1016/j.anai.2018.03.028

Bou Saab, J., Losa, D., Chanson, M., and Ruez, R. (2014). Connexins in respiratory and gastrointestinal mucosal immunity. FEBS Lett. 588, 1288-1296. doi: 10. 1016/j.febslet.2014.02.059

Bravo, D. T., Soudry, E., Edward, J. A., Le, W., Nguyen, A. L., Hwang, P. H., et al. (2013). Characterization of human upper airway epithelial progenitors. Int. Forum Allergy Rhinol. 3, 841-847. doi: 10.1002/alr.21205

Busse, W. W., Lemanske, R. F. Jr., and Gern, J. E. (2010). Role of viral respiratory infections in asthma and asthma exacerbations. Lancet 376, 826-834. doi: 10 . 1016/S0140-6736(10)61380-3

Carpagnano, G. E., Scioscia, G., Lacedonia, D., Soccio, P., Lepore, G., Saetta, M., et al. (2018). Looking for airways periostin in severe asthma: could it be useful for clustering type 2 endotype? Chest 154, 1083-1090. doi: 10.1016/j.chest.2018. 08.1032

Chen, X., Chang, L., Li, X., Huang, J., Yang, L., Lai, X., et al. (2018). Tc17/IL17A up-regulated the expression of MMP-9 via NF-kappaB pathway in nasal epithelial cells of patients with chronic rhinosinusitis. Front. Immunol. 9:2121. doi: 10.3389/fimmu.2018.02121

Cho, J. S., Kang, J. H., Um, J. Y., Han, I. H., Park, I. H., and Lee, H. M. (2014). Lipopolysaccharide induces pro-inflammatory cytokines and MMP production via TLR4 in nasal polyp-derived fibroblast and organ culture. PLoS One 9:e90683. doi: 10.1371/journal.pone.0090683

Cho, J. S., Kim, J. A., Park, J. H., Park, I. H., Han, I. H., and Lee, H. M. (2016). Tolllike receptor 4-mediated expression of interleukin-32 via the c-Jun $\mathrm{N}$-terminal kinase/protein kinase $\mathrm{B} / \mathrm{cyclic}$ adenosine monophosphate response element binding protein pathway in chronic rhinosinusitis with nasal polyps. Int. Forum Allergy Rhinol. 6, 1020-1028. doi: 10.1002/alr.21792

Clifford, R. L., Patel, J., MacIsaac, J. L., McEwen, L. M., Johnson, S. R., Shaw, D., et al. (2019). Airway epithelial cell isolation techniques affect DNA methylation profiles with consequences for analysis of asthma related perturbations to DNA methylation. Sci. Rep. 9:14409. doi: 10.1038/s41598-019-50873-y

Cohen, N. A. (2017). The genetics of the bitter taste receptor T2R38 in upper airway innate immunity and implications for chronic rhinosinusitis. Laryngoscope 127, 44-51. doi: 10.1002/lary.26198

Copeland, E., Leonard, K., Carney, R., Kong, J., Forer, M., Naidoo, Y., et al. (2018). Chronic rhinosinusitis: potential role of microbial dysbiosis and recommendations for sampling sites. Front. Cell. Infect. Microbiol. 8:57. doi: $10.3389 /$ fcimb.2018.00057

Cutting, G. R. (2005). Modifier genetics: cystic fibrosis. Annu. Rev. Genomics Hum. Genet. 6, 237-260. doi: 10.1146/annurev.genom.6.080604.162254

Deng, H., Sun, Y., Wang, W., Li, M., Yuan, T., Kong, W., et al. (2019). The hippo pathway effector Yes-associated protein promotes epithelial proliferation and remodeling in chronic rhinosinusitis with nasal polyps. Allergy 74, 731-742. doi: 10.1111/all.13647

Dickson, R. P., Erb-Downward, J. R., and Huffnagle, G. B. (2013). The role of the bacterial microbiome in lung disease. Expert Rev. Respir. Med. 7, 245-257. doi: 10.1586/ers.13.24

Dietz de Loos, D., Lourijsen, E. S., Wildeman, M. A. M., Freling, N. J. M., Wolvers, M. D. J., Reitsma, S., et al. (2019). Prevalence of chronic rhinosinusitis in the general population based on sinus radiology and symptomatology. J. Allergy Clin. Immunol. 143, 1207-1214. doi: 10.1016/j.jaci.2018.12.986

Earl, J. P., Adappa, N. D., Krol, J., Bhat, A. S., Balashov, S., Ehrlich, R. L., et al. (2018). Species-level bacterial community profiling of the healthy sinonasal microbiome using Pacific biosciences sequencing of full-length 16S rRNA genes. Microbiome 6:190. doi: 10.1186/s40168-018-0569-2

Ebenezer, J. A., Christensen, J. M., Oliver, B. G., Oliver, R. A., Tjin, G., Ho, J., et al. (2017). Periostin as a marker of mucosal remodelling in chronic rhinosinusitis. Rhinology 55, 234-241. doi: 10.4193/Rhin16.215

Ege, M. J., Mayer, M., Normand, A. C., Genuneit, J., Cookson, W. O., BraunFahrlander, C., et al. (2011). Exposure to environmental microorganisms and childhood asthma. N. Engl. J. Med. 364, 701-709. doi: 10.1056/NEJMoa1007302

El-Anwar, M. W., Hamed, A. A., Mohamed, A. E., Nofal, A. A., Mohamed, M. A., and Abdel-Aziz, H. R. (2015). Surfactant protein a expression in chronic rhinosinusitis and atrophic rhinitis. Int. Arch. Otorhinolaryngol. 19, 130-134. doi: $10.1055 / \mathrm{s}-0035-1546432$

Erle, D. J., and Sheppard, D. (2014). The cell biology of asthma. J. Cell Biol. 205, 621-631. doi: 10.1083/jcb.201401050

Fokkens, W. J., Lund, V. J., Mullol, J., Bachert, C., Alobid, I., Baroody, F., et al. (2012). EPOS 2012: European position paper on rhinosinusitis and nasal polyps 2012. A summary for otorhinolaryngologists. Rhinology 50, 1-12. doi: 10.4193/ Rhino50E2

Freund, J. R., Mansfield, C. J., Doghramji, L. J., Adappa, N. D., Palmer, J. N., Kennedy, D. W., et al. (2018). Activation of airway epithelial bitter taste receptors by Pseudomonas aeruginosa quinolones modulates calcium, cyclicAMP, and nitric oxide signaling. J. Biol. Chem. 293, 9824-9840. doi: 10.1074/ jbc.RA117.001005

Frohlich, M., Pinart, M., Keller, T., Reich, A., Cabieses, B., Hohmann, C., et al. (2017). Is there a sex-shift in prevalence of allergic rhinitis and comorbid asthma from childhood to adulthood? A meta-analysis. Clin. Transl. Allergy 7:44. doi: 10.1186/s13601-017-0176-5

Fukuoka, A., Matsushita, K., Morikawa, T., Adachi, T., Yasuda, K., Kiyonari, H., et al. (2019). Human cystatin $\mathrm{SN}$ is an endogenous protease inhibitor that prevents allergic rhinitis. J. Allergy Clin. Immunol. 143, 1153-1162.e12. doi: 10.1016/j.jaci.2018.06.035

Georas, S. N., and Rezaee, F. (2014). Epithelial barrier function: at the front line of asthma immunology and allergic airway inflammation. J. Allergy Clin. Immunol. 134, 509-520. doi: 10.1016/j.jaci.2014.05.049

GINA (2018). GINA Report: Global Strategy for Asthma Management and Prevention. Available online at: https:/ginasthma.org/wp-content/uploads/ 2018/04/wms-GINA-2018-report-V1.3-002.pdf (accessed November 15, 2019).

Golebski, K., Luiten, S., van Egmond, D., de Groot, E., Roschmann, K. I., Fokkens, W. J., et al. (2014). High degree of overlap between responses to a virus and to the house dust mite allergen in airway epithelial cells. PLoS One 9:e87768. doi: 10.1371/journal.pone.0087768

Goto, K., Chiba, Y., Sakai, H., and Misawa, M. (2009). Tumor necrosis factoralpha (TNF-alpha) induces upregulation of RhoA via NF-kappaB activation in 
cultured human bronchial smooth muscle cells. J. Pharmacol. Sci. 110, 437-444. doi: 10.1254/jphs.09081fp

Guan, W. J., Gao, Y. H., Li, H. M., Yuan, J. J., Chen, R. C., and Zhong, N. S. (2015). Impacts of co-existing chronic rhinosinusitis on disease severity and risks of exacerbations in Chinese adults with bronchiectasis. PLoS One 10:e0137348. doi: 10.1371/journal.pone. 0137348

Guan, W. J., Li, J. C., Liu, F., Zhou, J., Liu, Y. P., Ling, C., et al. (2018). Next-generation sequencing for identifying genetic mutations in adults with bronchiectasis. J. Thorac. Dis. 10, 2618-2630. doi: 10.21037/jtd.2018.04.134

Gudis, D., Zhao, K. Q., and Cohen, N. A. (2012). Acquired cilia dysfunction in chronic rhinosinusitis. Am. J. Rhinol. Allergy 26, 1-6. doi: 10.2500/ajra.2012. 26.3716

Guilemany, J. M., Angrill, J., Alobid, I., Centellas, S., Pujols, L., Bartra, J., et al. (2009). United airways again: high prevalence of rhinosinusitis and nasal polyps in bronchiectasis. Allergy 64, 790-797. doi: 10.1111/j.1398-9995.2008. 01892.x

Gupta, R., Sheikh, A., Strachan, D. P., and Anderson, H. R. (2004). Burden of allergic disease in the UK: secondary analyses of national databases. Clin. Exp. Allergy 34, 520-526. doi: 10.1111/j.1365-2222.2004.1935.x

Hallit, S., Raherison, C., Malaeb, D., Hallit, R., Waked, M., Kheir, N., et al. (2019). Development of an asthma risk factors scale (ARFS) for risk assessment asthma screening in children. Pediatr. Neonatol. 60, 156-165. doi: 10.1016/j.pedneo. 2018.05.009

Hamilos, D. L. (2016). Chronic rhinosinusitis in patients with cystic fibrosis. J. Allergy Clin. Immunol. Pract. 4, 605-612. doi: 10.1016/j.jaip.2016.04.013

Hammad, H., Chieppa, M., Perros, F., Willart, M. A., Germain, R. N., and Lambrecht, B. N. (2009). House dust mite allergen induces asthma via Tolllike receptor 4 triggering of airway structural cells. Nat. Med. 15, 410-416. doi: $10.1038 / \mathrm{nm} .1946$

Hanif, T., Dhaygude, K., Kankainen, M., Renkonen, J., Mattila, P., Ojala, T., et al. (2019). Birch pollen allergen immunotherapy reprograms nasal epithelial transcriptome and recovers microbial diversity. J. Allergy Clin. Immunol. 143, 2293-2296.e11. doi: 10.1016/j.jaci.2019.02.002

Hansel, T. T., Johnston, S. L., and Openshaw, P. J. (2013). Microbes and mucosal immune responses in asthma. Lancet 381, 861-873. doi: 10.1016/s01406736(12)62202-8

Hartshorn, K. L. (2010). Role of surfactant protein A and D (SP-A and SP-D) in human antiviral host defense. Front. Biosci. 2:s83. doi: 10.27 $41 / \mathrm{s} 83$

Hirota, T., Takahashi, A., Kubo, M., Tsunoda, T., Tomita, K., Doi, S., et al. (2011). Genome-wide association study identifies three new susceptibility loci for adult asthma in the Japanese population. Nat. Genet. 43, 893-896. doi: 10.1038/ng. 887

Hirsch, A. G., Nordberg, C., Bandeen-Roche, K., Tan, B. K., Schleimer, R. P., Kern, R. C., et al. (2019). Radiologic sinus inflammation and symptoms of chronic rhinosinusitis in a population-based sample. Allergy doi: 10.1111/all.14106 [Epub ahead of print].

Hoggard, M., Wagner Mackenzie, B., Jain, R., Taylor, M. W., Biswas, K., and Douglas, R. G. (2017). Chronic rhinosinusitis and the evolving understanding of microbial ecology in chronic inflammatory mucosal disease. Clin. Microbiol. Rev. 30, 321-348. doi: 10.1128/cmr.00060-16

Homma, T., Kato, A., Sakashita, M., Takabayashi, T., Norton, J. E., Suh, L. A., et al. (2017). Potential involvement of the epidermal growth factor receptor ligand epiregulin and matrix metalloproteinase-1 in pathogenesis of chronic rhinosinusitis. Am. J. Respir. Cell Mol. Biol. 57, 334-345. doi: 10.1165/rcmb. 2016-0325OC

Hsu, J., Avila, P. C., Kern, R. C., Hayes, M. G., Schleimer, R. P., and Pinto, J. M. (2013). Genetics of chronic rhinosinusitis: state of the field and directions forward. J. Allergy Clin. Immunol. 131, 977-993.e5. doi: 10.1016/j.jaci.2013.01. 028

Hu, H., and Li, H. (2018). Prunetin inhibits lipopolysaccharide-induced inflammatory cytokine production and MUC5AC expression by inactivating the TLR4/MyD88 pathway in human nasal epithelial cells. Biomed. Pharmacother. 106, 1469-1477. doi: 10.1016/j.biopha.2018.07.093

Huang, Y. J., Nariya, S., Harris, J. M., Lynch, S. V., Choy, D. F., Arron, J. R., et al. (2015). The airway microbiome in patients with severe asthma: associations with disease features and severity. J. Allergy Clin. Immunol. 136, 874-884. doi: 10.1016/j.jaci.2015.05.044
Hupin, C., Gohy, S., Bouzin, C., Lecocq, M., Polette, M., and Pilette, C. (2014). Features of mesenchymal transition in the airway epithelium from chronic rhinosinusitis. Allergy 69, 1540-1549. doi: 10.1111/all.12503

Ilmarinen, P., Tuomisto, L. E., and Kankaanranta, H. (2015). Phenotypes, risk factors, and mechanisms of adult-onset asthma. Mediators Inflamm. 2015:514868. doi: 10.1155/2015/514868

Ishida, A., Ohta, N., Suzuki, Y., Kakehata, S., Okubo, K., Ikeda, H., et al. (2012). Expression of pendrin and periostin in allergic rhinitis and chronic rhinosinusitis. Allergol. Int. 61, 589-595. doi: 10.2332/allergolint.11-OA-0370

Jardeleza, C., Miljkovic, D., Baker, L., Boase, S., Tan, N. C., Koblar, S. A., et al. (2013). Inflammasome gene expression alterations in Staphylococcus aureus biofilm-associated chronic rhinosinusitis. Rhinology 51, 315-322. doi: 10.4193/ Rhin 13.045

Jarvis, D., Newson, R., Lotvall, J., Hastan, D., Tomassen, P., Keil, T., et al. (2012). Asthma in adults and its association with chronic rhinosinusitis: the GA2LEN survey in Europe. Allergy 67, 91-98. doi: 10.1111/j.1398-9995.2011.02709.x

Jiang, Z., and Zhu, L. (2016). Update on the role of alternatively activated macrophages in asthma. J. Asthma Allergy 9, 101-107. doi: 10.2147/JAA. S104508

Jiao, J., Duan, S., Meng, N., Li, Y., Fan, E., and Zhang, L. (2015). Role of IFNgamma, IL-13, and IL-17 on mucociliary differentiation of nasal epithelial cells in chronic rhinosinusitis with nasal polyps. Clin. Exp. Allergy 46, 449-460. doi: $10.1111 /$ cea. 12644

Jiao, J., Wang, C., and Zhang, L. (2019). Epithelial physical barrier defects in chronic rhinosinusitis. Expert Rev. Clin. Immunol. 15, 679-688. doi: 10.1080/ 1744666X.2019.1601556

Jiao, J., Wang, M., Duan, S., Meng, Y., Meng, N., Li, Y., et al. (2018). Transforming growth factor-betal decreases epithelial tight junction integrity in chronic rhinosinusitis with nasal polyps. J. Allergy Clin. Immunol. 141, 1160-1163.e9. doi: 10.1016/j.jaci.2017.08.045

Joenvaara, S., Mattila, P., Renkonen, J., Makitie, A., Toppila-Salmi, S., Lehtonen, M., et al. (2009). Caveolar transport through nasal epithelium of birch pollen allergen Bet $\mathrm{v} 1$ in allergic patients. J. Allergy Clin. Immunol. 124, 135-142.e1-21. doi: 10.1016/j.jaci.2008.11.048

Juhn, Y. J. (2014). Risks for infection in patients with asthma (or other atopic conditions): is asthma more than a chronic airway disease? J. Allergy Clin. Immunol. 134, 247-257: quiz 58-59.

Juncadella, I. J., Kadl, A., Sharma, A. K., Shim, Y. M., Hochreiter-Hufford, A., Borish, L., et al. (2013). Apoptotic cell clearance by bronchial epithelial cells critically influences airway inflammation. Nature 493, 547-551. doi: 10.1038/ nature11714

Kaur, R., and Chupp, G. (2019). Phenotypes and endotypes of adult asthma: moving toward precision medicine. J. Allergy Clin. Immunol. 144, 1-12. doi: 10.1016/j.jaci.2019.05.031

Khlifi, R., Olmedo, P., Gil, F., Hammami, B., and Hamza-Chaffai, A. (2015). Cadmium and nickel in blood of Tunisian population and risk of nasosinusal polyposis disease. Environ. Sci. Pollut. Res. 22, 3586-3593. doi: 10.1007/s11356014-3619-8

Kim, B., Lee, H. J., Im, N. R., Lee, D. Y., Kang, C. Y., Park, I. H., et al. (2018). Effect of matrix metalloproteinase inhibitor on disrupted E-cadherin after acid exposure in the human nasal epithelium. Laryngoscope 128, E1-E7. doi: 10. 1002/lary.26932

Kim, K. W., and Ober, C. (2019). Lessons learned from GWAS of asthma. Allergy Asthma Immunol. Res. 11, 170-187.

Kim, R., Chang, G., Hu, R., Phillips, A., and Douglas, R. (2016). Connexin gap junction channels and chronic rhinosinusitis. Int. Forum Allergy Rhinol. 6, 611-617. doi: 10.1002/alr.21717

Knight, R., Vrbanac, A., Taylor, B. C., Aksenov, A., Callewaert, C., Debelius, J., et al. (2018). Best practices for analysing microbiomes. Nat. Rev. Microbiol. 16, 410-422. doi: 10.1038/s41579-018-0029-9

Knowles, M. R., Daniels, L. A., Davis, S. D., Zariwala, M. A., and Leigh, M. W. (2013). Primary ciliary dyskinesia. Recent advances in diagnostics, genetics, and characterization of clinical disease. Am. J. Respir. Crit. Care Med. 188, 913-922. doi: 10.1164/rccm.201301-0059CI

Kohanski, M. A., Workman, A. D., Patel, N. N., Hung, L.-Y., Shtraks, J. P., Chen, B., et al. (2018). Solitary chemosensory cells are a primary epithelial source of IL-25 in patients with chronic rhinosinusitis with nasal polyps. J. Allergy Clin. Immunol. 142, 460-469.e7. doi: 10.1016/j.jaci.2018.03.019 
Kountakis, S. E., Arango, P., Bradley, D., Wade, Z. K., and Borish, L. (2004). Molecular and cellular staging for the severity of chronic rhinosinusitis. Laryngoscope 114, 1895-1905. doi: 10.1097/01.mlg.0000147917.43615.c0

Kouzaki, H., Matsumoto, K., Kato, T., Tojima, I., Shimizu, S., and Shimizu, T. (2016). Epithelial cell-derived cytokines contribute to the pathophysiology of eosinophilic chronic rhinosinusitis. J. Interferon Cytokine Res. 36, 169-179. doi: 10.1089/jir.2015.0058

Kristjansson, R. P., Benonisdottir, S., Davidsson, O. B., Oddsson, A., Tragante, V., Sigurdsson, J. K., et al. (2019). A loss-of-function variant in ALOX15 protects against nasal polyps and chronic rhinosinusitis. Nat. Genet. 51, 267-276. doi: 10.1038/s41588-018-0314-6

Kudo, M., Ishigatsubo, Y., and Aoki, I. (2013). Pathology of asthma. Front. Microbiol. 4:263.

Kuhar, H. N., Tajudeen, B. A., Mahdavinia, M., Gattuso, P., Ghai, R., and Batra, P. S. (2017). Inflammatory infiltrate and mucosal remodeling in chronic rhinosinusitis with and without polyps: structured histopathologic analysis. Int. Forum Allergy Rhinol. 7, 679-689. doi: 10.1002/alr.21943

Lal, D., Keim, P., Delisle, J., Barker, B., Rank, M. A., Chia, N., et al. (2017). Mapping and comparing bacterial microbiota in the sinonasal cavity of healthy, allergic rhinitis, and chronic rhinosinusitis subjects. Int. Forum Allergy Rhinol. 7, 561-569. doi: 10.1002/alr.21934

Lam, K., Schleimer, R., and Kern, R. C. (2015). The etiology and pathogenesis of chronic rhinosinusitis: a review of current hypotheses. Curr. Allergy Asthma Rep. 15:41. doi: 10.1007/s11882-015-0540-2

Lambrecht, B. N., and Hammad, H. (2012). The airway epithelium in asthma. Nat. Med. 18, 684-692. doi: 10.1038/nm.2737

Lambrecht, B. N., and Hammad, H. (2014). Allergens and the airway epithelium response: gateway to allergic sensitization. J. Allergy Clin. Immunol. 134, 499507. doi: 10.1016/j.jaci.2014.06.036

Lan, B., Mitchel, J. A., O’Sullivan, M. J., Park, C. Y., Kim, J. H., Cole, W. C., et al. (2018). Airway epithelial compression promotes airway smooth muscle proliferation and contraction. Am. J. Physiol. Lung Cell. Mol. Physiol. 315, L645-L652. doi: 10.1152/ajplung.00261.2018

Laury, A. M., Hilgarth, R., Nusrat, A., and Wise, S. K. (2015). Periostin and receptor activator of nuclear factor kappa-B ligand expression in allergic fungal rhinosinusitis. Int. Forum Allergy Rhinol. 4, 716-724. doi: 10.1002/alr.21367

Lee, R. J., and Cohen, N. A. (2014). Bitter and sweet taste receptors in the respiratory epithelium in health and disease. J. Mol. Med. 92, 1235-1244. doi: 10.1007/s00109-014-1222-6

Lehmann, A. E., Scangas, G. A., Bergmark, R. W., El Rassi, E., Stankovic, K. M., and Metson, R. (2019). Periostin and inflammatory disease: implications for chronic rhinosinusitis. Otolaryngol. Head Neck Surg. 160, 965-973. doi: 10. 1177/0194599819838782

Li, J., and Li, Y. (2019). Autophagy is involved in allergic rhinitis by inducing airway remodeling. Int. Forum Allergy Rhinol. 9, 1346-1351. doi: 10.1002/alr.22424

Li, X., Tao, Y., and Li, X. (2015). Expression of MMP-9/TIMP-2 in nasal polyps and its functional implications. Int. J. Clin. Exp. Pathol. 8, 14556-14561.

Li, Y., Wang, X., Wang, R., Bo, M., Fan, E., Duan, S., et al. (2014). The expression of epithelial intercellular junctional proteins in the sinonasal tissue of subjects with chronic rhinosinusitis: a histopathologic study. ORL J. Otorhinolaryngol. Relat. Spec. 76, 110-119. doi: 10.1159/000362246

Li, Y. Y., Li, C. W., Chao, S. S., Yu, F. G., Yu, X. M., Liu, J., et al. (2014). Impairment of cilia architecture and ciliogenesis in hyperplastic nasal epithelium from nasal polyps. J. Allergy Clin. Immunol. 134, 1282-1292. doi: 10.1016/j.jaci.2014.07. 038

Li, Z., Zeng, M., Deng, Y., Zhao, J., Zhou, X., Trudeau, J. B., et al. (2019). 15Lipoxygenase 1 in nasal polyps promotes CCL26/eotaxin 3 expression through extracellular signal-regulated kinase activation. J. Allergy Clin. Immunol. 144, 1228-1241.e9. doi: 10.1016/j.jaci.2019.06.037

Liao, B., Hu, C. Y., Liu, T., and Liu, Z. (2014). Respiratory viral infection in the chronic persistent phase of chronic rhinosinusitis. Laryngoscope 124, 832-837. doi: 10.1002/lary.24348

Licona-Limon, P., Kim, L. K., Palm, N. W., and Flavell, R. A. (2013). TH2, allergy and group 2 innate lymphoid cells. Nat. Immunol. 14, 536-542. doi: 10.1038/ni. 2617

Lin, H., Li, Z., Lin, D., Zheng, C., and Zhang, W. (2016). Role of NLRP3 inflammasome in eosinophilic and non-eosinophilic chronic rhinosinusitis with nasal polyps. Inflammation 39, 2045-2052. doi: 10.1007/s10753-0160442-z

Lisspers, K., Janson, C., Larsson, K., Johansson, G., Telg, G., Thuresson, M., et al. (2018). Comorbidity, disease burden and mortality across age groups in a Swedish primary care asthma population: an epidemiological register study (PACEHR). Respir. Med. 136, 15-20. doi: 10.1016/j.rmed.2018.01.020

Liu, C., Li, Y., Yu, J., Feng, L., Hou, S., Liu, Y., et al. (2013). Targeting the shift from M1 to M2 macrophages in experimental autoimmune encephalomyelitis mice treated with fasudil. PLoS One 8:e54841. doi: 10.1371/journal.pone.0054841

London, N. R. Jr., and Ramanathan, M. Jr. (2017). The role of the sinonasal epithelium in allergic rhinitis. Otolaryngol. Clin. North Am. 50, 1043-1050. doi: 10.1016/j.otc.2017.08.002

Lopez-Souza, N., Favoreto, S., Wong, H., Ward, T., Yagi, S., Schnurr, D., et al. (2009). In vitro susceptibility to rhinovirus infection is greater for bronchial than for nasal airway epithelial cells in human subjects. J. Allergy Clin. Immunol. 123, 1384-1390.e2. doi: 10.1016/j.jaci.2009.03.010

Luukkainen, A., Puan, K. J., Yusof, N., Lee, B., Tan, K. S., Liu, J., et al. (2018). A coculture model of PBMC and stem cell derived human nasal epithelium reveals rapid activation of $\mathrm{NK}$ and innate $\mathrm{T}$ cells upon influenza $\mathrm{A}$ virus infection of the nasal epithelium. Front. Immunol. 9:2514. doi: 10.3389/fimmu.2018.02514

Ma, Y., Sun, Y., Jiang, L., Zuo, K., Chen, H., Guo, J., et al. (2017). WDPCP regulates the ciliogenesis of human sinonasal epithelial cells in chronic rhinosinusitis. Cytoskeleton 74, 82-90. doi: 10.1002/cm.21351

Maeda, Y., Chen, G., Xu, Y., Haitchi, H. M., Du, L., Keiser, A. R., et al. (2011). Airway epithelial transcription factor NK2 homeobox 1 inhibits mucous cell metaplasia and Th2 inflammation. Am. J. Respir. Crit. Care Med. 184, 421-429. doi: 10.1164/rccm.201101-0106OC

Malinsky, R. R., Valera, F. C., Cavallari, F. E., Kupper, D. S., Milaneze, C., Silva, J. S., et al. (2013). Matrix metalloproteinases and their impact on sinusal extension in chronic rhinosinusitis with nasal polyps. Eur. Arch. Otorhinolaryngol. 270, 1345-1348. doi: 10.1007/s00405-012-2219-9

Martin, F. J., and Prince, A. S. (2008). TLR2 regulates gap junction intercellular communication in airway cells. J. Immunol. 180, 4986-4993. doi: 10.4049/ jimmunol.180.7.4986

Mattila, P., Renkonen, J., Toppila-Salmi, S., Parviainen, V., Joenvaara, S., AlffTuomala, S., et al. (2010). Time-series nasal epithelial transcriptomics during natural pollen exposure in healthy subjects and allergic patients. Allergy 65, 175-183. doi: 10.1111/j.1398-9995.2009.02181.x

McDougall, C. M., Blaylock, M. G., Douglas, J. G., Brooker, R. J., Helms, P. J., and Walsh, G. M. (2008). Nasal epithelial cells as surrogates for bronchial epithelial cells in airway inflammation studies. Am. J. Respir. Cell Mol. Biol. 39, 560-568. doi: 10.1165/rcmb.2007-0325OC

McKiernan, P. J., Molloy, K., Cryan, S. A., McElvaney, N. G., and Greene, C. M. (2014). Long noncoding RNA are aberrantly expressed in vivo in the cystic fibrosis bronchial epithelium. Int. J. Biochem. Cell Biol. 52, 184-191. doi: 10. 1016/j.biocel.2014.02.022

Mésidor, M., Benedetti, A., El-Zein, M., Menzies, D., Parent, M. -É, and Rousseau, M.-C. (2019). Asthma phenotypes based on health services use for allergic diseases in a province-wide birth cohort. Ann. Allergy Asthma Immunol. 122, 50-57.e2. doi: 10.1016/j.anai.2018.09.453

Milonski, J., Zielinska-Blizniewska, H., Przybylowska, K., Pietkiewicz, P., Korzycka-Zaborowska, B., Majsterek, I., et al. (2015). Significance of CYCLOOXYGENASE-2(COX-2), PERIOSTIN (POSTN) and INTERLEUKIN4(IL-4) gene expression in the pathogenesis of chronic rhinosinusitis with nasal polyps. Eur. Arch. Otorhinolaryngol. 272, 3715-3720. doi: 10.1007/s00405-0143481-9

Monick, M. M., Yarovinsky, T. O., Powers, L. S., Butler, N. S., Carter, A. B., Gudmundsson, G., et al. (2003). Respiratory syncytial virus up-regulates TLR4 and sensitizes airway epithelial cells to endotoxin. J. Biol. Chem. 278, 5303553044. doi: 10.1074/jbc.m308093200

Morris, A., Beck, J. M., Schloss, P. D., Campbell, T. B., Crothers, K., Curtis, J. L., et al. (2013). Comparison of the respiratory microbiome in healthy nonsmokers and smokers. Am. J. Respir. Crit. Care Med. 187, 1067-1075.

Muluk, N. B., Arikan, O. K., Atasoy, P., Kilic, R., and Yalcinozan, E. T. (2015). The role of MMP-2, MMP-9, and TIMP-1 in the pathogenesis of nasal polyps: immunohistochemical assessment at eight different levels in the epithelial, subepithelial, and deep layers of the mucosa. Ear Nose Throat J. 94, E1-E13. 
Numata, M., Chu, H. W., Dakhama, A., and Voelker, D. R. (2010). Pulmonary surfactant phosphatidylglycerol inhibits respiratory syncytial virus-induced inflammation and infection. Proc. Natl. Acad. Sci. USA 107, 320-325. doi: 10.1073/pnas.0909361107

Nunes, C., Pereira, A. M., and Morais-Almeida, M. (2017). Asthma costs and social impact. Asthma Res. Pract. 3:1.

Ohta, N., Ishida, A., Kurakami, K., Suzuki, Y., Kakehata, S., Ono, J., et al. (2014). Expressions and roles of periostin in otolaryngological diseases. Allergol. Int. 63, 171-180. doi: 10.2332/allergolint.13-RAI-0673

Ordovas-Montanes, J., Dwyer, D. F., Nyquist, S. K., Buchheit, K. M., Vukovic, M., Deb, C., et al. (2018). Allergic inflammatory memory in human respiratory epithelial progenitor cells. Nature 560, 649-654. doi: 10.1038/s41586-01 8-0449-8

Osorio, F., Lambrecht, B., and Janssens, S. (2013). The UPR and lung disease. Semin. Immunopathol. 35, 293-306. doi: 10.1007/s00281-013-0368-6

Oyer, S. L., Nagel, W., and Mulligan, J. K. (2013). Differential expression of adhesion molecules by sinonasal fibroblasts among control and chronic rhinosinusitis patients. Am. J. Rhinol. Allergy 27, 381-386. doi: 10.2500/ajra. 2013.27.3934

Pace, E., Ferraro, M., Siena, L., Melis, M., Montalbano, A. M., Johnson, M., et al. (2008). Cigarette smoke increases Toll-like receptor 4 and modifies lipopolysaccharide-mediated responses in airway epithelial cells. Immunology 124, 401-411. doi: 10.1111/j.1365-2567.2007.02788.x

Pallasaho, P., Ronmark, E., Haahtela, T., Sovijarvi, A. R., and Lundback, B. (2006). Degree and clinical relevance of sensitization to common allergens among adults: a population study in Helsinki, Finland. Clin. Exp. Allergy 36, 503-509. doi: 10.1111/j.1365-2222.2006.02460.x

Park, S. K., Jin, S. Y., Yeon, S. H., Lee, S. B., Xu, J., Yoon, Y. H., et al. (2018). Role of Toll-like receptor 9 signaling on activation of nasal polyp-derived fibroblasts and its association with nasal polypogenesis. Int. Forum Allergy Rhinol. 8, 1001-1012. doi: 10.1002/alr.22155

Peric, A., Mirkovic, C. S., and Vojvodic, D. (2018). Clara cell protein 16 release from the nasal mucosa in allergic rhinitis, chronic rhinosinusitis, and exposure to air pollutants. Arh. Hig. Rada. Toksikol. 69, 215-219. doi: 10.2478/aiht-201869-3081

Peterson, S., Poposki, J. A., Nagarkar, D. R., Chustz, R. T., Peters, A. T., Suh, L. A., et al. (2012). Increased expression of CC chemokine ligand 18 in patients with chronic rhinosinusitis with nasal polyps. J. Allergy Clin. Immunol. 129, 119-127.e1-9. doi: 10.1016/j.jaci.2011.08.021

Pividori, M., Schoettler, N., Nicolae, D. L., Ober, C., and Im, H. K. (2019). Shared and distinct genetic risk factors for childhood-onset and adult-onset asthma: genome-wide and transcriptome-wide studies. Lancet Respir. Med. 7, 509-522. doi: 10.1016/S2213-2600(19)30055-4

Polosa, R., and Thomson, N. C. (2013). Smoking and asthma: dangerous liaisons. Eur. Respir. J. 41, 716-726. doi: 10.1183/09031936.00073312

Pols, D. H. J., Wartna, J. B., Moed, H., van Alphen, E. I., Bohnen, A. M., and Bindels, P. J. E. (2016). Atopic dermatitis, asthma and allergic rhinitis in general practice and the open population: a systematic review. Scand. J. Prim. Health Care 34, 143-150. doi: 10.3109/02813432.2016.1160629

Poole, A., Urbanek, C., Eng, C., Schageman, J., Jacobson, S., O’Connor, B. P., et al. (2014). Dissecting childhood asthma with nasal transcriptomics distinguishes subphenotypes of disease. J. Allergy Clin. Immunol. 133, 670-678.e12. doi: 10.1016/j.jaci.2013.11.025

Popatia, R., Haver, K., and Casey, A. (2014). Primary ciliary dyskinesia: an update on new diagnostic modalities and review of the literature. Pediatr. Allergy Immunol. Pulmonol. 27, 51-59. doi: 10.1089/ped.2013.0314

Pothoven, K. L., Norton, J. E., Hulse, K. E., Suh, L. A., Carter, R. G., Rocci, E., et al. (2015). Oncostatin M promotes mucosal epithelial barrier dysfunction, and its expression is increased in patients with eosinophilic mucosal disease. J. Allergy Clin. Immunol. 136, 737-746.e4. doi: 10.1016/j.jaci.2015.01.043

Pothoven, K. L., and Schleimer, R. P. (2017). The barrier hypothesis and oncostatin M: restoration of epithelial barrier function as a novel therapeutic strategy for the treatment of type 2 inflammatory disease. Tissue Barriers 5:e1341367. doi: 10.1080/21688370.2017.1341367

Ramezanpour, M., Moraitis, S., Smith, J. L., Wormald, P. J., and Vreugde, S. (2016). Th17 cytokines disrupt the airway mucosal barrier in chronic rhinosinusitis. Mediators Inflamm. 2016:9798206. doi: 10.1155/2016/9798206
Rehl, R. M., Balla, A. A., Cabay, R. J., Hearp, M. L., Pytynia, K. B., and Joe, S. A. (2007). Mucosal remodeling in chronic rhinosinusitis. Am. J. Rhinol. 21, 651-657. doi: 10.2500/ajr.2007.21.3096

Renkonen, J., Toppila-Salmi, S., Joenvaara, S., Mattila, P., Parviainen, V., Hagstrom, J., et al. (2015). Expression of Toll-like receptors in nasal epithelium in allergic rhinitis. APMIS 123, 716-725. doi: 10.1111/apm.12408

Roberts, N., Al Mubarak, R., Francisco, D., Kraft, M., and Chu, H. W. (2018). Comparison of paired human nasal and bronchial airway epithelial cell responses to rhinovirus infection and IL-13 treatment. Clin. Transl. Med. 7:13. doi: 10.1186/s40169-018-0189-2

Roschmann, K. I., Luiten, S., Jonker, M. J., Breit, T. M., Fokkens, W. J., Petersen, A., et al. (2011). Timothy grass pollen extract-induced gene expression and signalling pathways in airway epithelial cells. Clin. Exp. Allergy 41, 830-841. doi: 10.1111/j.1365-2222.2011.03713.x

Roscioli, E., Jersmann, H. P., Lester, S., Badiei, A., Fon, A., Zalewski, P., et al. (2017). Zinc deficiency as a codeterminant for airway epithelial barrier dysfunction in an ex vivo model of COPD. Int. J. Chron. Obstruct. Pulmon. Dis. 12, 3503-3510. doi: 10.2147/COPD.S149589

Ryu, G., and Kim, D. W. (2020). Th2 inflammatory responses in the development of nasal polyps and chronic rhinosinusitis. Curr. Opin. Allergy Clin. Immunol. 20, 1-8. doi: 10.1097/aci.0000000000000588

Saulyte, J., Regueira, C., Montes-Martinez, A., Khudyakov, P., and Takkouche, B. (2014). Active or passive exposure to tobacco smoking and allergic rhinitis, allergic dermatitis, and food allergy in adults and children: a systematic review and meta-analysis. PLoS Med. 11:e1001611. doi: 10.1371/journal.pmed. 1001611

Scadding, G. (2014). Cytokine profiles in allergic rhinitis. Curr. Allergy Asthma Rep.o 14:435.

Schleimer, R. P. (2017). Immunopathogenesis of chronic rhinosinusitis and nasal polyposis. Annu. Rev. Pathol. 12, 331-357. doi: 10.1146/annurev-pathol052016-100401

Schleimer, R. P., and Berdnikovs, S. (2017). Etiology of epithelial barrier dysfunction in patients with type 2 inflammatory diseases. J. Allergy Clin. Immunol. 139, 1752-1761. doi: 10.1016/j.jaci.2017.04.010

Schoettler, N., Rodriguez, E., Weidinger, S., and Ober, C. (2019). Advances in asthma and allergic disease genetics - is bigger always better? J. Allergy Clin. Immunol.144, 1495-1506. doi: 10.1016/j.jaci.2019.10.023

Seshadri, S., Lin, D. C., Rosati, M., Carter, R. G., Norton, J. E., Suh, L., et al. (2012). Reduced expression of antimicrobial PLUNC proteins in nasal polyp tissues of patients with chronic rhinosinusitis. Allergy 67, 920-928. doi: 10.1111/j.13989995.2012.02848.x

Shapouri-Moghaddam, A., Mohammadian, S., Vazini, H., Taghadosi, M., Esmaeili, S. A., Mardani, F., et al. (2018). Macrophage plasticity, polarization, and function in health and disease. J. Cell. Physiol. 233, 6425-6440. doi: 10.1002/ jcp. 26429

Sharma, N., Akkoyunlu, M., and Rabin, R. L. (2017). Macrophages-common culprit in obesity and asthma. Allergy. 73, 1196-1205. doi: 10.1111/all.13369

Shi, L. L., Xiong, P., Zhang, L., Cao, P. P., Liao, B., Lu, X., et al. (2013). Features of airway remodeling in different types of Chinese chronic rhinosinusitis are associated with inflammation patterns. Allergy 68, 101-109. doi: 10.1111/all. 12064

Shimizu, S., Kouzaki, H., Kato, T., Tojima, I., and Shimizu, T. (2016). HMGB1TLR4 signaling contributes to the secretion of interleukin 6 and interleukin 8 by nasal epithelial cells. Am. J. Rhinol. Allergy 30, 167-172. doi: 10.2500/ajra. 2016.30.4300

Shimizu, S., Ogawa, T., Takezawa, K., Tojima, I., Kouzaki, H., and Shimizu, T. (2015). Tissue factor and tissue factor pathway inhibitor in nasal mucosa and nasal secretions of chronic rhinosinusitis with nasal polyp. Am. J. Rhinol. Allergy 29, 235-242. doi: 10.2500/ajra.2015.29.4183

Shimizu, S., Tojima, I., Takezawa, K., Matsumoto, K., Kouzaki, H., and Shimizu, T. (2017). Thrombin and activated coagulation factor $\mathrm{X}$ stimulate the release of cytokines and fibronectin from nasal polyp fibroblasts via protease-activated receptors. Am. J. Rhinol. Allergy 31, 13-18. doi: 10.2500/ajra.2017.31.4400

Shin, S. H., Kim, Y. H., Jin, H. S., and Kang, S. H. (2016a). Alternaria induces production of thymic stromal lymphopoietin in nasal fibroblasts through tolllike receptor 2. Allergy Asthma Immunol. Res. 8, 63-68. doi: 10.4168/aair.2016. 8.1 .63 
Shin, S. H., Ye, M. K., Kim, Y. H., and Kim, J. K. (2016b). Role of TLRs in the production of chemical mediators in nasal polyp fibroblasts by fungi. Auris Nasus Larynx 43, 166-170. doi: 10.1016/j.anl.2015.07.003

Shiono, O., Sakuma, Y., Komatsu, M., Hirama, M., Yamashita, Y., Ishitoya, J., et al. (2015). Differential expression of periostin in the nasal polyp may represent distinct histological features of chronic rhinosinusitis. Auris Nasus Larynx 42, 123-127. doi: 10.1016/j.anl.2014.09.003

Sica, A., and Mantovani, A. (2012). Macrophage plasticity and polarization: in vivo veritas. J. Clin. Invest. 122, 787-795. doi: 10.1172/JCI59643

Sigurs, N., Bjarnason, R., Sigurbergsson, F., and Kjellman, B. (2000). Respiratory syncytial virus bronchiolitis in infancy is an important risk factor for asthma and allergy at age 7. Am. J. Respir. Crit. Care Med. 161, 1501-1507. doi: 10.1164/ajrccm.161.5.9906076

Soyka, M. B., Wawrzyniak, P., Eiwegger, T., Holzmannm, D., Treis, A., Wanke, K., et al. (2012). Defective epithelial barrier in chronic rhinosinusitis: the regulation of tight junctions by IFN-gamma and IL-4. J. Allergy Clin. Immunol. 130, 1087-1096.e10. doi: 10.1016/j.jaci.2012.05.052

Stentzel, S., Teufelberger, A., Nordengrun, M., Kolata, J., Schmidt, F., van Crombruggen, K., et al. (2017). Staphylococcal serine protease-like proteins are pacemakers of allergic airway reactions to Staphylococcus aureus. J. Allergy Clin. Immunol. 139, 492-500.e8. doi: 10.1016/j.jaci.2016.03.045

Sterner, T., Uldahl, A., Svensson, A., Bjork, J., Svedman, C., Nielsen, C., et al. (2019). The southern Sweden adolescent allergy-cohort: prevalence of allergic diseases and cross-sectional associations with individual and social factors. J. Asthma 56, 227-235. doi: 10.1080/02770903.2018.1452033

Sun, Y., Zhou, B., Wang, C., Huang, Q., Zhang, Q., Han, Y., et al. (2012). Biofilm formation and Toll-like receptor 2, Toll-like receptor 4, and NF-kappaB expression in sinus tissues of patients with chronic rhinosinusitis. Am. J. Rhinol. Allergy 26, 104-109. doi: 10.2500/ajra.2012.26.3718

Suzuki, H., Koizumi, H., Ikezaki, S., Tabata, T., Ohkubo, J., Kitamura, T., et al. (2016). Electrical impedance and expression of tight junction components of the nasal turbinate and polyp. ORL J. Otorhinolaryngol. Relat. Spec. 78, 16-25. doi: $10.1159 / 000442024$

Suzuki, M., Itoh, M., Ohta, N., Nakamura, Y., Moriyama, A., Matsumoto, T., et al. (2006). Blocking of protease allergens with inhibitors reduces allergic responses in allergic rhinitis and other allergic diseases. Acta Otolaryngol. 126, 746-751. doi: 10.1080/00016480500475625

Suzuki, M., Ramezanpour, M., Cooksley, C., Li, J., Nakamaru, Y., Homma, A., et al. (2018). Sirtuin-1 controls Poly (I:C)-dependent matrix metalloproteinase 9 activation in primary human nasal epithelial cells. Am. J. Respir. Cell Mol. Biol. 59, 500-510. doi: 10.1165/rcmb.2017-0415OC

Takabayashi, T., Kato, A., Peters, A. T., Hulse, K. E., Suh, L. A., Carter, R., et al. (2013). Excessive fibrin deposition in nasal polyps caused by fibrinolytic impairment through reduction of tissue plasminogen activator expression. Am. J. Respir. Crit. Care Med. 187, 49-57. doi: 10.1164/rccm.201207-1292OC

Takabayashi, T., Tanaka, Y., Susuki, D., Yoshida, K., Tomita, K., Sakashita, M., et al. (2019). Increased expression of L-plastin in nasal polyp of patients with nonsteroidal anti-inflammatory drug-exacerbated respiratory disease. Allergy 74, 1307-1316. doi: 10.1111/all.13677

Tan, A. M., Chen, H. C., Pochard, P., Eisenbarth, S. C., Herrick, C. A., and Bottomly, H. K. (2010). TLR4 signaling in stromal cells is critical for the initiation of allergic Th2 responses to inhaled antigen. J. Immunol. 184, 35353544. doi: 10.4049/jimmunol.0900340

Tengroth, L., Arebro, J., Kumlien Georen, S., Winqvist, O., and Cardell, L. O. (2014a). Deprived TLR9 expression in apparently healthy nasal mucosa might trigger polyp-growth in chronic rhinosinusitis patients. PLoS One 9:e105618. doi: 10.1371 /journal.pone. 0105618

Tengroth, L., Millrud, C. R., Kvarnhammar, A. M., Kumlien Georen, S., Latif, L., and Cardell, L. O. (2014b). Functional effects of Toll-like receptor (TLR)3, 7, 9, RIG-I and MDA-5 stimulation in nasal epithelial cells. PLoS One 9:e98239. doi: 10.1371/journal.pone.0098239

Thai, P., Loukoianov, A., Wachi, S., and Wu, R. (2008). Regulation of airway mucin gene expression. Annu. Rev. Physiol. 70, 405-429. doi: 10.1146/annurev. physiol.70.113006.100441

Tharakan, A., Halderman, A. A., Lane, A. P., Biswal, S., and Ramanathan, M. Jr. (2016). Reversal of cigarette smoke extract-induced sinonasal epithelial cell barrier dysfunction through Nrf2 Activation. Int. Forum Allergy Rhinol. 6, 1145-1150. doi: 10.1002/alr.21827
Tieu, D. D., Peters, A. T., Carter, R. G., Suh, L., Conley, D. B., Chandra, R., et al. (2010). Evidence for diminished levels of epithelial psoriasin and calprotectin in chronic rhinosinusitis. J. Allergy Clin. Immunol. 125, 667-675. doi: 10.1016/ j.jaci.2009.11.045

Tipirneni, K. E., Zhang, S., Cho, D. Y., Grayson, J., Skinner, D. F., Mackey, C., et al. (2018). Submucosal gland mucus strand velocity is decreased in chronic rhinosinusitis. Int. Forum Allergy Rhinol. 8, 509-512. doi: 10.1002/alr.22065

Tokunaga, Y., Imaoka, H., Kaku, Y., Kawayama, T., and Hoshino, T. (2019). The significance of CD163-expressing macrophages in asthma. Ann. Allergy Asthma Immunol. 123, 263-270. doi: 10.1016/j.anai.2019.05.019

Tomassen, P., Vandeplas, G., Van Zele, T., Cardell, L. O., Arebro, J., Olze, H., et al. (2016). Inflammatory endotypes of chronic rhinosinusitis based on cluster analysis of biomarkers. J. Allergy Clin. Immunol. 137, 1449-1456.e4. doi: 10. 1016/j.jaci.2015.12.1324

Tomaszewska, M., Sarnowska, E., Rusetska, N., Kowalik, K., Sierdzinski, J., Siedlecki, J. A., et al. (2019). Role of vitamin D and its receptors in the pathophysiology of chronic rhinosinusitis. J. Am. Coll. Nutr. 38, 108-118. doi: 10.1080/07315724.2018.1503102

Toppila-Salmi, S., Chanoine, S., Karjalainen, J., Pekkanen, J., Bousquet, J., and Siroux, V. (2019). Risk of adult-onset asthma increases with the number of allergic multimorbidities and decreases with age. Allergy 74, 2406-2416. doi: 10.1111/all.13971

Toppila-Salmi, S., van Drunen, C. M., Fokkens, W. J., Golebski, K., Mattila, P., Joenvaara, S., et al. (2015). Molecular mechanisms of nasal epithelium in rhinitis and rhinosinusitis. Curr. Allergy Asthma Rep. 15:495.

Toskala, E., and Kennedy, D. W. (2015). Asthma risk factors. Int. Forum Allergy Rhinol. 5(Suppl. 1), S11-S16.

Tourdot, S., Mathie, S., Hussell, T., Edwards, L., Wang, H., Openshaw, P. J., et al. (2008). Respiratory syncytial virus infection provokes airway remodelling in allergen-exposed mice in absence of prior allergen sensitization. Clin. Exp. Allergy 38, 1016-1024. doi: 10.1111/j.1365-2222.2008.02974.x

Tsai, Y. J., Chi, J. C., Hao, C. Y., and Wu, W. B. (2018). Peptidoglycan induces bradykinin receptor 1 expression through Toll-like receptor 2 and NF-kappaB signaling pathway in human nasal mucosa-derived fibroblasts of chronic rhinosinusitis patients. J. Cell. Physiol. 233, 7226-7238. doi: 10.1002/jcp. 26553

Tsybikov, N. N., Egorova, E. V., Kuznik, B. I., Fefelova, E. V., and Magen, E. (2016). Biomarker assessment in chronic rhinitis and chronic rhinosinusitis: endothelin-1, TARC/CCL17, neopterin, and alpha-defensins. Allergy Asthma Proc. 37, 35-42. doi: 10.2500/aap.2016.37.3899

Tyner, J. W., Kim, E. Y., Ide, K., Pelletier, M. R., Roswit, W. T., Morton, J. D., et al. (2006). Blocking airway mucous cell metaplasia by inhibiting EGFR antiapoptosis and IL-13 transdifferentiation signals. J. Clin. Invest. 116, 309-321. doi: $10.1172 /$ jci25167

Van Bruaene, N., and Bachert, C. (2011). Tissue remodeling in chronic rhinosinusitis. Curr. Opin. Allergy Clin. Immunol. 11, 8-11. doi: 10.1097/aci. 0b013e32834233ef

Vercelli, D., and Bleecker, E. R. (2019). Strength in numbers: the quest for asthma genes. J. Allergy Clin. Immunol. 144, 413-415. doi: 10.1016/j.jaci.2019. 06.007

Vonk, J. M., Nieuwenhuis, M. A. E., Dijk, F. N., Boudier, A., Siroux, V., Bouzigon, E., et al. (2018). Novel genes and insights in complete asthma remission: a genome-wide association study on clinical and complete asthma remission. Clin. Exp. Allergy 48, 1286-1296. doi: 10.1111/cea.13181

Voynow, J. A., and Rubin, B. K. (2009). Mucins, mucus, and sputum. Chest 135, 505-512. doi: 10.1378/chest.08-0412

Wagener, A. H., Zwinderman, A. H., Luiten, S., Fokkens, W. J., Bel, E. H., Sterk, P. J., et al. (2014). dsRNA-induced changes in gene expression profiles of primary nasal and bronchial epithelial cells from patients with asthma, rhinitis and controls. Respir. Res. 15:9. doi: 10.1186/1465-9921-15-9

Wang, L. F., Chien, C. Y., Chiang, F. Y., Chai, C. Y., and Tai, C. F. (2012). Corelationship between matrix metalloproteinase 2 and 9 expression and severity of chronic rhinosinusitis with nasal polyposis. Am. J. Rhinol. Allergy 26, e1-e4. doi: 10.2500/ajra.2012.26.3724

Wang, M., Wang, X., Zhang, N., Wang, H., Li, Y., Fan, E., et al. (2015). Association of periostin expression with eosinophilic inflammation in nasal polyps. J. Allergy Clin. Immunol. 136, 1700-1703.e9. doi: 10.1016/j.jaci.2015. 09.005 
Wang, X., Moylan, B., Leopold, D. A., Kim, J., Rubenstein, R. C., Togias, A., et al. (2000). Mutation in the gene responsible for cystic fibrosis and predisposition to chronic rhinosinusitis in the general population. JAMA 284, 1814-1819.

Wei, Y., Ma, R., Zhang, J., Wu, X., Yu, G., Hu, X., et al. (2018). Excessive periostin expression and Th2 response in patients with nasal polyps: association with asthma. J. Thorac. Dis. 10, 6585-6597. doi: 10.21037/jtd.2018.11.12

Wenzel, S. E. (2012). Asthma phenotypes: the evolution from clinical to molecular approaches. Nat. Med. 18, 716-725. doi: 10.1038/nm.2678

Westphalen, K., Gusarova, G. A., Islam, M. N., Subramanian, M., Cohen, T. S., Prince, A. S., et al. (2014). Sessile alveolar macrophages communicate with alveolar epithelium to modulate immunity. Nature 506, 503-506. doi: 10.1038/ nature 12902

Whitsett, J. A., and Alenghat, T. (2015). Respiratory epithelial cells orchestrate pulmonary innate immunity. Nat. Immunol. 16, 27-35. doi: 10.1038/ni. 3045

Whitsett, J. A., Wert, S. E., and Weaver, T. E. (2010). Alveolar surfactant homeostasis and the pathogenesis of pulmonary disease. Annu. Rev. Med. 61, 105-119. doi: 10.1146/annurev.med.60.041807.123500

Wiksten, J., Toppila-Salmi, S., and Makela, M. (2018). Primary prevention of airway allergy. Curr. Treat. Options Allergy 5, 347-355. doi: 10.1007/s40521018-0190-4

Willis-Owen, S. A. G., Cookson, W. O. C., and Moffatt, M. F. (2018). The genetics and genomics of asthma. Annu. Rev. Genomics Hum. Genet. 19, 223-246. doi: 10.1146/annurev-genom-083117-021651

Wise, S. K., Lin, S. Y., Toskala, E., Orlandi, R. R., Akdis, C. A., Alt, J. A., et al. (2018). International consensus statement on allergy and rhinology: allergic rhinitis. Int. Forum Allergy Rhinol. 8, 108-352.

Wu, D., Wei, Y., and Bleier, B. S. (2018). Emerging role of proteases in the pathogenesis of chronic rhinosinusitis with nasal polyps. Front. Cell. Infect. Microbiol. 7:538. doi: 10.3389/fcimb.2017.00538

Xiang, R., Zhang, Q. P., Zhang, W., Kong, Y. G., Tan, L., Chen, S. M., et al. (2019). Different effects of allergic rhinitis on nasal mucosa remodeling in chronic rhinosinusitis with and without nasal polyps. Eur. Arch. Otorhinolaryngol. 276, 115-130. doi: 10.1007/s00405-018-5195-X

Xu, J., Lee, J. W., Park, S. K., Lee, S. B., Yoon, Y. H., Yeon, S. H., et al. (2014). Tolllike receptor 9 ligands increase type I interferon induced B-cell activating factor expression in chronic rhinosinusitis with nasal polyposis. Clin. Immunol. 197, 19-26. doi: 10.1016/j.clim.2018.07.014

Xu, M., Chen, D., Zhou, H., Zhang, W., Xu, J., and Chen, L. (2017). The role of periostin in the occurrence and progression of eosinophilic chronic sinusitis with nasal polyps. Sci. Rep. 7:9479. doi: 10.1038/s41598-017-08375-2

Yamin, M., Holbrook, E. H., Gray, S. T., Busaba, N. Y., Lovett, B., and Hamilos, D. L. (2015). Profibrotic transforming growth factor beta 1 and activin A are increased in nasal polyp tissue and induced in nasal polyp epithelium by cigarette smoke and Toll-like receptor 3 ligation. Int. Forum Allergy Rhinol. 5, 573-582. doi: 10.1002/alr.21516

Yang, H. W., Park, J. H., Shin, J. M., and Lee, H. M. (2018). Glucocorticoids ameliorate periostin-induced tissue remodeling in chronic rhinosinusitis with nasal polyps. Clin. Exp. Allergy 10, 10. doi: 10.1111/cea.13267 [Epub ahead of print].

Yang, L. Y., Li, X., Li, W. T., Huang, J. C., Wang, Z. Y., Huang, Z. Z., et al. (2017). Vgammal+ gammadeltaT cells are correlated with increasing expression of eosinophil cationic protein and metalloproteinase-7 in chronic rhinosinusitis with nasal polyps inducing the formation of edema. Allergy Asthma Immunol. Res. 9, 142-151. doi: 10.4168/aair.2017.9.2.142

Yeo, N. K., Eom, D. W., Oh, M. Y., Lim, H. W., and Song, Y. J. (2013). Expression of matrix metalloproteinase 2 and 9 and tissue inhibitor of metalloproteinase 1 in nonrecurrent vs recurrent nasal polyps. Ann. Allergy Asthma Immunol. 111, 205-210. doi: 10.1016/j.anai.2013.06.023

Yilmaz, O. H., Katajisto, P., Lamming, D. W., Gultekin, Y., Bauer-Rowe, K. E., Sengupta, S., et al. (2012). mTORC1 in the Paneth cell niche couples intestinal stem-cell function to calorie intake. Nature 486, 490-495. doi: 10.1038/ nature 11163

Yoo, F., and Suh, J. D. (2017). What is the evidence for genetics in chronic rhinosinusitis? Curr. Opin. Otolaryngol. Head Neck Surg. 25, 54-63. doi: 10. 1097/MOO.0000000000000329

Yu, X. M., Li, C. W., Li, Y. Y., Liu, J., Lin, Z. B., Li, T. Y., et al. (2013). Downregulation of EMP1 is associated with epithelial hyperplasia and metaplasia in nasal polyps. Histopathology 63, 686-695. doi: 10.1111/his.12211

Zhang, Y. L., Chen, P. X., Guan, W. J., Guo, H. M., Qiu, Z. E., Xu, J. W., et al. (2018). Increased intracellular $\mathrm{Cl}$ concentration promotes ongoing inflammation in airway epithelium. Mucosal Immunol. 11, 1149-1157. doi: 10.1038/s41385-0180013-8

Conflict of Interest: ST-S has acted as paid consultant for ERT and Roche Products. RK has acted as a consultant for Sanofi-Regeneron, GSK, Genentech, Astellas, Lyra Therapeutics. All these are outside the submitted work.

The remaining authors declare that the research was conducted in the absence of any commercial or financial relationships that could be construed as a potential conflict of interest.

Copyright (c) 2020 Laulajainen-Hongisto, Toppila-Salmi, Luukkainen and Kern. This is an open-access article distributed under the terms of the Creative Commons Attribution License (CC BY). The use, distribution or reproduction in other forums is permitted, provided the original author(s) and the copyright owner(s) are credited and that the original publication in this journal is cited, in accordance with accepted academic practice. No use, distribution or reproduction is permitted which does not comply with these terms. 